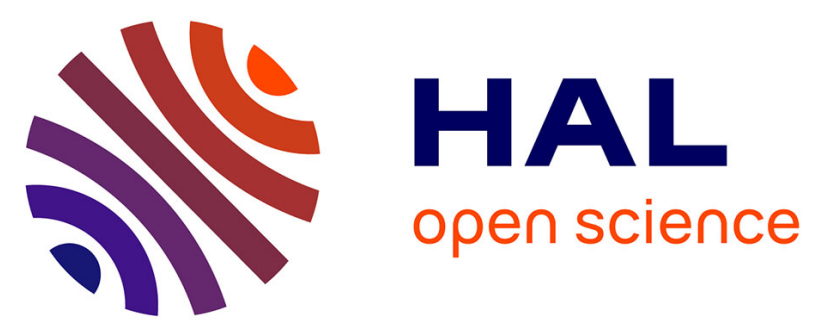

\title{
Life Cycle Assessment of low temperature asphalt mixtures for road pavement surfaces: a comparative analysis
}

João Santos, Sarah Bressi, Veronique Cerezo, Michel Dauvergne, Davide Lo Presti

\section{To cite this version:}

João Santos, Sarah Bressi, Veronique Cerezo, Michel Dauvergne, Davide Lo Presti. Life Cycle Assessment of low temperature asphalt mixtures for road pavement surfaces: a comparative analysis. Resources, Conservation and Recycling, 2018, 138, pp.283-297. 10.1016/j.resconrec.2018.07.012 . hal02053210

\section{HAL Id: hal-02053210 https://hal.science/hal-02053210}

Submitted on 1 Mar 2019

HAL is a multi-disciplinary open access archive for the deposit and dissemination of scientific research documents, whether they are published or not. The documents may come from teaching and research institutions in France or abroad, or from public or private research centers.
L'archive ouverte pluridisciplinaire $\mathbf{H A L}$, est destinée au dépôt et à la diffusion de documents scientifiques de niveau recherche, publiés ou non, émanant des établissements d'enseignement et de recherche français ou étrangers, des laboratoires publics ou privés. 
1 LCA of low temperature asphalt mixtures for road pavement surfaces: a 2 comparative analysis

3 Joao Santos, PhD (Corresponding Author)

4 IFSTTAR, AME-EASE, Route de Bouaye, CS4, F-44341 Bouguenais, France.

5 Email: santosjmo@gmail.com

6 Sara Bressi, PhD

7 Department of Civil and Industrial Engineering (DICI), University of Pisa, Largo L. Lazzarino, Pisa, 8 Italy

9 Véronique Cerezo, PhD

10 IFSTTAR, AME-EASE, Route de Bouaye, CS4, F-44341 Bouguenais, France.

11 Michel Dauvergne

12 IFSTTAR, AME-EASE, Route de Bouaye, CS4, F-44341 Bouguenais, France.

13 Davide Lo Presti, PhD

14 Nottingham Transportation Engineering Centre, University of Nottingham Faculty of Engineering, The 15 University of Nottingham, University Park, Nottingham, NG7 2RD.

16

17 


\section{LCA of low temperature asphalt mixtures for road pavement surfaces: a 2 comparative analysis}

\section{Abstract}

The increasing fuel consumption demand, the accelerated pressure imposed by the depletion of scarce raw materials and the urgent environmental protection requirements are forcing the change of pavement industry and academia community's research endeavors towards the development of low emissions road paving technologies able to significantly reduce mixing and compaction temperature as well as the consumption of virgin raw materials. One set of relatively recent technologies in the field of pavement materials that aims at addressing those concerns are the warm mix asphalt (WMA). In fact, they have the potential to allow the reduction of energy consumption and airborne emissions during their production and placement. Moreover, the incorporation of reclaimed asphalt pavement (RAP) in these mixtures may further improve their potential environmental sustainability, both by reducing the consumption of virgin raw materials, and by reducing the stockpiles and landfills of milled materials. Which of these sustainable practices is greener and whether combining them is promising as it sounds, it's still not actually too well demonstrated in literature.

It's within this context that this study presents a full process-based comparative life cycle assessment (LCA) looking at understanding the environmental impact of reducing mixing temperature , through the use of warm mix technologies, namely chemical additives-based and foamed-based, and different rate of recycling ( $0 \%$ and 50\% RAP). Furthermore, the investigation explores the effect of combining the effects in the construction, maintenance and rehabilitation (M\&R) of wearing courses for flexible road pavements. The analysis assessed the functional units over a 30-year project analysis period (PAP), considering all pavement life cycle phases: extraction of raw materials and production; transportation of materials; construction, maintenance and rehabilitation; work zone traffic management; usage and end-of-life. The results of this study showed that, for the conditions considered and assumptions performed, a pavement construction and M\&R scenario in which a foamed-based WMA mixture with a RAP content of 50\% is employed in the wearing course throughout the pavement life cycle is the most environmentally friendly alternative among all the competing solutions. Moreover, the results of a scenario analysis showed that the life cycle environmental impacts could be reduced if the asphalt plant was fueled by natural gas, or if the pavement structure was dismantled at the end of its lifetime and the debris recycled.

Keywords: life cycle assessment (LCA); war mix asphalt (WMA); chemical additives; hot mix asphalt (HMA); reclaimed asphalt pavement (RAP); sustainable pavement construction and management. 


\section{Introduction}

Considerable amount of Greenhouse gases (GHG) and airborne pollutants are released into the atmosphere during the energy intensive asphalt mixtures production process (Thives and Ghisi, 2017). As GHG and their effect on the climate are increasingly in the spotlight with respect to policy, legislation and general public's concern, the pavement industry and scientific community have been challenged to improve conventional asphalt mixtures production processes by developing more sustainable technologies and behaviors.

One example of the specific engagement of research institutions and enterprises in developing and delivering multi-faceted and sound solutions meant to mitigate the environmental pressure originated by the sector's activities is the SUP\&R ITN (Sustainable Pavement \& Rail Initial Training Network) research project (http://superitn.eu/wp/) (Lo Presti et al., 2017).

The SUP\&R ITN is a training-through-research program, which through a multidisciplinary and multi-sectorial network, aims (1) to form a new generation of engineers versed in sustainable technologies for road pavement and railways and (2) to provide, to both academia and industry, design procedures and sustainability assessment methodologies to certify the sustainability of the studied technologies to the benefit of the European community. Some of the promising sustainable technologies commonly mentioned in the literature and studied in the framework of this research project are the asphalt mixes requiring lower manufacturing temperatures, such as (1) warm mix asphalt (WMA) (Kristjánsdóttir et al., 2007; Hamzah et al., 2010; Tatari et al., 2012; Vidal et al., 2013; Mohammad et al., 2015; Rodríguez-Alloza et al., 2015; Almeida-Costa and Benta, 2016; Stimilli et al., 2017), (2) halfwarm mix asphalt (HWMA) (Rubio et al., 2013) and (3) cold mix asphalt technologies (FHWA, 2016).

WMA is the name used to designate a set of technologies by which the traditional HMA is allowed to be manufactured, transported, placed and compacted at lower temperatures. Characteristically, the mixing temperatures of HMA vary from 150 to $180^{\circ} \mathrm{C}$ (Jones, 2004), whereas for WMA and HWMA they are comprised between 100 and $140^{\circ} \mathrm{C}$, and between 60 and $100^{\circ} \mathrm{C}$, respectively. In addition to the mixing temperature reduction, the list of benefits that come with the use of these technologies is completed with the following items (Rubio et al., 2013): (1) reduced emissions; (2) better working conditions due to the absence of harmful gases; (3) quicker turnover to traffic; (4) longer hauling distances; and (5) extended paving window. Furthermore, the potential sustainability of such solutions may be further broadened through the partial or full replacement of virgin and/or manufactured materials with recycled, co-product, or waste materials (RCWM), from which the reclaimed asphalt pavement (RAP), recycled concrete aggregate (RCA), recycled asphalt shingles (RAS), air-cooled blast furnace slag (ACBFS), steel furnace slag (SFS), foundry sand, etc., (Van Dam et al., 2016) are examples.

In order to prove quantitatively the theoretical environmental benefits to which the aforementioned technologies are associated with, the most significant environmental inputs and outputs over their life cycle, from raw materials production to the end of the technologies' life, should be assessed. This can be accomplished through life cycle assessment (LCA). LCA is a data-driven, systematic methodology, to investigate, estimate, and evaluate the environmental burdens caused by a material, product, process, or service throughout its life span (Matthews et al., 2015). The life cycle begins at the acquisition of raw materials, evolves through several distinct stages (material processing, manufacturing and use), and terminates at the product end-of-life (EOL).

\subsection{State-of-the-art of LCA studies on WMA technologies}

Several research studies have been performed that apply the LCA methodology to measure the potential life cycle environmental impacts of the processes involving the production and placement of the WMA technologies in lieu of conventional HMA. Tatari et al. (2012) developed a thermodynamicbased hybrid LCA model to evaluate the environmental impacts from an ecological resource accounting 
perspective of three types of WMA mixtures and compare them to those of a conventional HMA mixture. The following WMA technologies were assessed: Aspha-Min ${ }^{\circledR}$, Sasobit ${ }^{\circledR}$, and Evotherm ${ }^{\circledR}$ WMA. Vidal et al. (2013) performed a comprehensive LCA of road pavements including HMA and zeolite-based WMA, both with and without RAP content. The ReCiPe method was used to assess the environmental impacts according to two sets of impact categories: midpoint and endpoint categories. Additionally, the cumulative energy demand indicator was adopted to compare the mixtures in terms of energy consumption. Mohammad et al. (2014) compared the environmental performance of two WMA technologies, namely foaming and Sasobit ${ }^{\circledR}$ additive, to that of a conventional HMA mixture, in terms of energy consumption at the asphalt plant and $\mathrm{CO}$ and $\mathrm{CO}_{2}$ emissions monitored during their production and placement. Rodríguez-Alloza et al. (2015) performed a comprehensive hybrid inputoutput-based LCA of the production of Fischer Tropsch (F-T) wax-based WMA mixtures with and without crumb-rubber modified (CRM) binders. The potential benefits of that WMA technology in relation to a conventional HMA were quantified by accounting for the embodied energy requirement and GHG emissions in the supply chain. Giani et al. (2015) carried out a process-based LCA in collaboration with an Italian asphalt-producing company with the objective of quantifying the potential environmental benefits resulting from constructing asphalt pavement using an unspecified type of WMA with the incorporation of up to $30 \%$ of RAP. Almeida-Costa and Benta (2016) quantified the potential benefits of two WMA technologies, Rediset ${ }^{\circledR}$ and Sasobit ${ }^{\circledR}$ additives, in relation to a conventional HMA mixture, by assessing the energy consumption and GHG emissions associated with their production. In turn, Yang et al. (2017) compared the environmental performance of crumb-rubber modified HMA and Evotherm ${ }^{\circledR}$ WMA to that of a conventional HMA mixture, expressed in terms of energy consumption and hazard emissions associated with their production.

\subsection{Aim and purpose of the study}

Notwithstanding the merits of the studies listed previously in showing the potential environmental benefits of some WMA technologies, mostly in terms of energy consumption and emissions released during their production, several aspects can be pointed out which underpin the need of expanding the knowledge in this domain: (1) there is still a wide range of other WMA technologies equally worthy of being thoroughly analyzed; (2) the role of the upstream supply chain related to the production of chemical additives used in WMA mixtures is commonly excluded from the system boundaries; (3) the existing studies tend to narrow the system boundaries by focusing on a few life cycle phases, usually the materials extraction, mixtures production and construction phases, and thus excluding phases (i.e., work zone (WZ) traffic management, usage and EOL), which depending on the technical context, might drive the environmental performance of the system being analysed. Moreover, while the consideration of the last point is not methodologically wrong, provided that a given set of conditions are met, it constraints a more global view of the system and thereby opportunities for eventually more meaningful environmental improvements.

Given the issues abovementioned, this research study aims to perform a comprehensive and methodologically sounded pavement LCA of a road pavement section incorporating several WMA technologies (i.e., chemical additives and foamed-based), both with and without RAP content, which covers all the pavement life cycle phases, from raw material acquisition, via production and use phases, to the EOL phase.

The overall purpose is to increase the pavement community stakeholders' capacity to make more strategic and informed decisions regarding the construction and M\&R of road pavement that would ultimately enhance the sustainability of pavement systems. 


\section{Methodology}

A comparative process-based LCA study is performed taking into account the ISO 14040 series (ISO, 2006a; ISO, 2006b) and the Federal Highway Administration's (FHWA's) Pavement LCA Framework (Harvey et al., 2016). It calculates and compares the potential environmental impacts of different asphalt mixtures adopted in the construction and $M \& R$ of a road pavement section during its life cycle.

The stages adopted in this study include goal and scope definition, inventory analysis, impact assessment, and interpretation.

\subsection{Goal and scope definition}

\subsubsection{Goal}

The main goal of this paper is to quantify the potential life cycle environmental impacts of a flexible road pavement section throughout its life cycle. The road pavement section studied involves the use of conventional and low-temperature asphalt mixes, with and without RAP content, in the construction, maintenance and rehabilitation $(M \& R)$ of wearing courses of the flexible road pavements.

The comparative findings of this study are intended to be used by highway agencies and pavement practitioners to make more assertive judgments on the pros and contras associated with the use of emerging and commonly called sustainable strategies and practices for road pavement construction and M\&R.

\subsubsection{System description and boundaries}

The system boundaries define the unit processes considered in the LCA study and were drawn to cover the pavement life cycle from a cradle-to-grave perspective, and to enable the performance of a parallel life cycle costs analysis in the near future.

Figure 1 presents the pavement life cycle phases and processes included within the system boundaries of the proposed pavement LCA model as well as their positioning towards relevant literature for the subject. Specifically, the system boundaries entail six pavement life cycle phases, modeled through individual but interconnected modules. They are the following: (1) extraction of materials and mixtures production, consisting of the acquisition and processing of raw materials, and the mixing process of asphalt mixtures in plant; (2) construction and $M \& R$, including all construction and $M \& R$ procedures and related construction equipment usage; (3) transportation of materials, accounting for the transportation of materials to and from the construction site and between intermediate facilities (e.g., transportation of aggregates from the quarries to asphalt mixing plants, etc.); (4) WZ traffic management phase. The WZ traffic management costs consist of the additional costs borne by the road users (RUC) when facing a disruption of the normal traffic flow as a consequence of the constraints imposed by a WZ traffic management plan; (5) usage, which addresses the interactions of the pavement with vehicles and environment throughout the project analysis period (PAP); and (6) EOL, which models the destination of the pavement structure after the PAP.

The analysis boundaries for the road pavement were set at the sub-base and at the finished road surface. They include (1) the construction of all layers contained by the limits stated above and subsequent M\&R activities; (2) the extraction of the materials needed to produce the mixtures used in those layers; and (3) the movement involved in hauling materials between facilities, between facilities and work site, and vice-versa. Furthermore, given the comparative nature of the study, it might have been decided to constraint the LCA system boundaries to the construction and M\&R of the wearing course. However, the whole pavement structure was taken into account in order to enable the acquirement of knowledge on the relative contribution of each pavement life cycle phases to the total life cycle impact scores. 


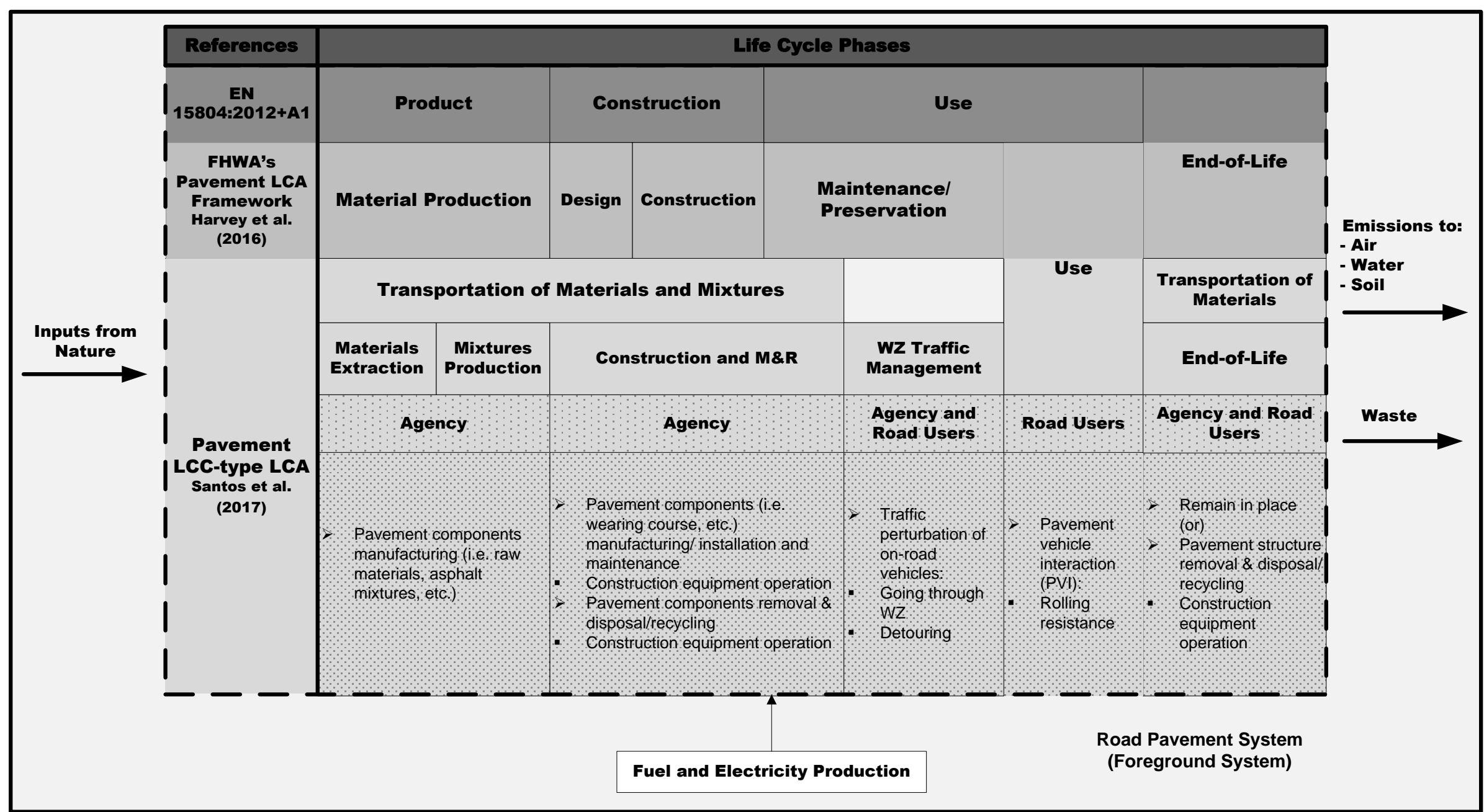

Background System

2 Figure 1. Pavement life cycle phases and processes included in the system boundaries and their positioning towards relevant literature for the subject. (Acronyms: 3 LCA- life cycle assessment; LCC- life cycle costs; M\&R- maintenance and rehabilitation; WZ- work zone) 
As far as the system boundaries for RAP are concerned, it is assumed that prior to its utilization the material is processed via a crushing operation, which reduces the variable RAP fragments to uniform size in order to promote final blend consistency. The environmental burdens resulting from milling or removing the pavement and hauling the debris from the work site to the recycling unit were not included into the system boundaries on the basis of a "cut-off" approach (Schrijvers et al., 2016a), which is the most-widely used procedure to handle the EOL phase in pavements LCAs (Aurangzeb et al., 2014). According to this approach, if a product is recycled at the EOL phase, no impacts for waste management are considered. The impacts of the recycling process are attributed to the second life cycle (Schrijvers et al., 2016b). Thus, the post-processing of the debris materials towards their transformation into usable RAP is only accounted for when considering the production of new mixtures which incorporate RAP into their composition. To accomplish the RAP processing task, a crusher unit located within the asphalt plant facility is considered, which consists of (1) a diesel-powered crusher, (2) a diesel-powered mobile screening plant, (3) an electrically-powered stackable conveyor and (4) a wheel loader.

The upstream emissions and resources consumption associated with the production of the energy sources used to power the different processes, construction equipment, and on-road vehicles were also included in the system boundaries. On the other hand, construction equipment, road-related safety and signaling equipment (including road marking), road accessories (fences, road lighting software, etc.), and the earthworks required to build the platform over which the pavement foundation will be built were not included in the system boundaries. The earthworks were excluded because the potential environmental impacts related to those works are better handled when performing a road LCA, as they are specific to a particular project. This fact makes it unsuitable for the general application of a pavement LCA model as it is intended in this case study.

Various supplementary sub-models that are attached to the corresponding modules, as well as the data required to run those models, are introduced and discussed later in this paper.

\subsubsection{Functional unit}

The functional unit is the central core of any LCA and forms the basis for comparisons between different systems with the same utility for the same function. In the pavement domain, this means a unit of pavement that can safely and efficiently carry the same traffic over the same project analysis period (PAP). Then, it is defined by their geometry, service life, and levels of traffic supported.

\subsubsection{Case study features: traffic, service life, pavement structure and maintenance and rehabilitation strategy}

The functional unit of the case study presented in this paper is a typical French highway section of 1-km length, composed of two independent roadways, each with 2 lanes with an individual width of $3.5 \mathrm{~m}$. The PAP is 30 years, starting in 2015 . The initial two-way average annual daily traffic (AADT) was considered to be equal to 6500 vehicles/day, of which $33 \%$ are heavy duty vehicles (HDV) equally divided between rigid HDV and articulated HDV. The structure and composition of the French fleet of vehicles, expressed in terms of type of vehicles and European emissions standards, was that defined by CITEPA (Centre Interprofessionnel Technique d'Études de la Pollution Atmosphérique). The traffic growth rate was set equal to $1.5 \%$ per year (Jullien et al., 2015). The geometric characteristics of the pavement structure adopted in each of the independent roadways are presented in Figure 2. A flexible road pavement structure was selected because this type of pavement represents the overwhelming majority of the total extension of the French highway network.

As for pavement maintenance, a pavement $M \& R$ strategy derived from French practice was considered (Jullien et al., 2014; Jullien et al., 2015). Figure 2 displays the maintenance tasks inherent to each M\&R activity as well as the application timing. They were assumed to be the same irrespective of the type of mixture applied in the wearing course. This assumption is supported by research studies 
1 showing that HMA and WMA pavements have comparable long-term field performance in terms of structural durability (Washington State University et al., 2017) and the inexistence of solid scientific evidences that functional properties of HMA and WMA pavements will evolve distinctively over time.

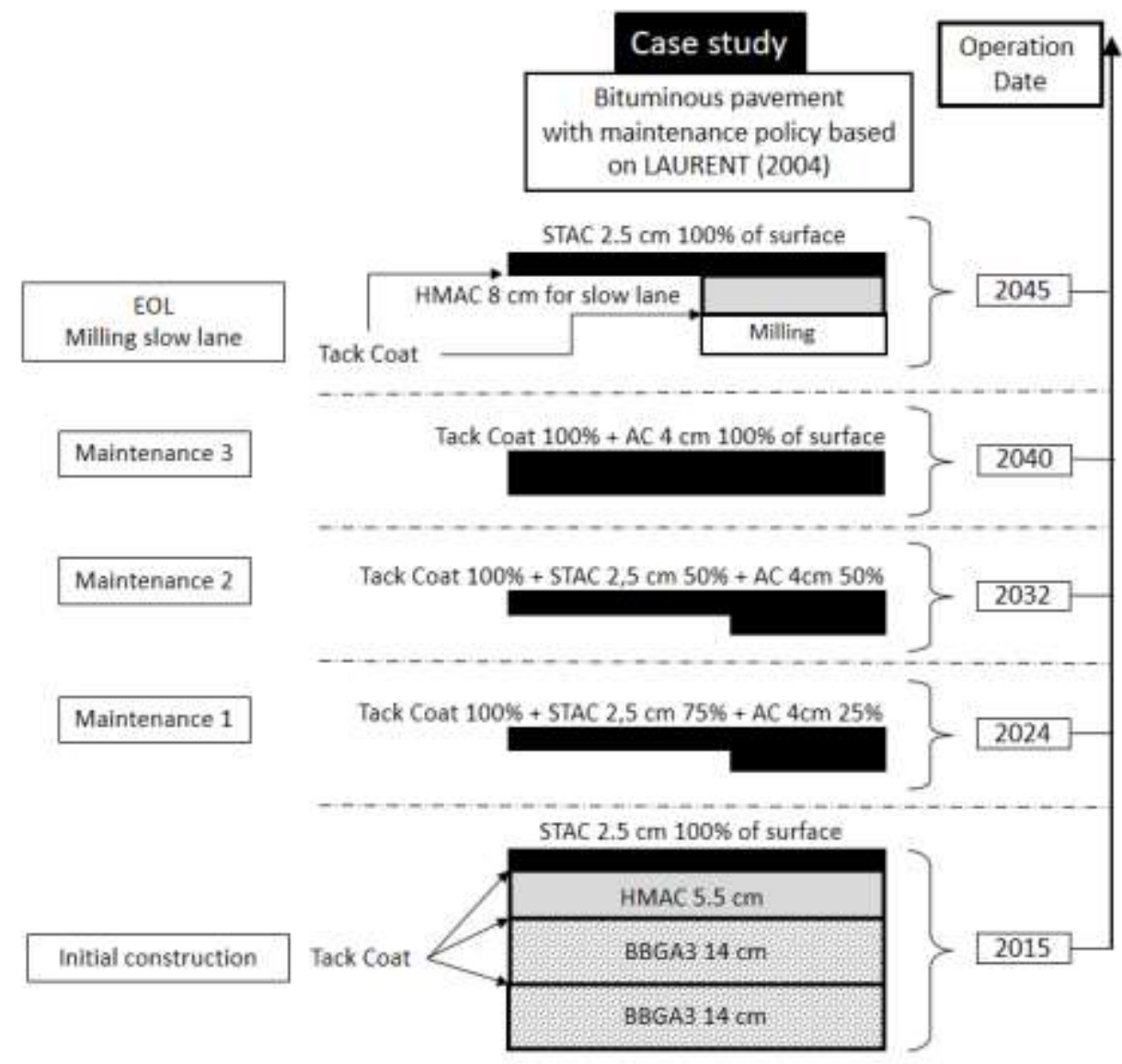

Figure 2. Geometric characteristics of the flexible pavement structure and M\&R strategy. (Acronyms: BBGA- bituminous bound graded aggregate; HMAC- hot mix asphalt concrete; STAC- super thin asphalt concrete; AC- asphalt concrete)

\subsubsection{Case study features: mixtures composition}

In order to understand the potential environmental advantages and disadvantages related to the use, in wearing courses, of low-temperature asphalt mixes with and without RAP content, the reference pavement structure (Figure 2) constituted by layers made of conventional HMA without RAP content was compared to four alternative structures with equal geometry, but in which the wearing course of the initial structure, and subsequent M\&R treatments, was made of WMA produced according with two different technologies (i.e., foaming and $\mathrm{CECABASE}^{\circledR}$ additive) to lower the manufacturing temperature, and with and without the adding of RAP. Furthermore, the set of alternative mixtures was completed with the consideration of a conventional HMA with a RAP content equal to $50 \%$, thus rising to 6 the total number of pavement sections to be analysed and compared. Table 1 presents the features of the several mixtures analyzed in the case study, which were investigated in the scope of the SUP\&R ITN research project (Lo Presti et al., 2017).

Table 1. Features of the bituminous mixtures used in all pavement structures studied. 


\begin{tabular}{|c|c|c|c|c|c|c|}
\hline & $\begin{array}{l}\text { HMA, } 0 \% \\
\text { RAP }\end{array}$ & $\begin{array}{l}\text { WMA- } \\
\text { CECABASE }^{\circledR}, \\
0 \% \text { RAP }\end{array}$ & $\begin{array}{l}\text { Foamed } \\
\text { WMA, 0\% } \\
\text { RAP }\end{array}$ & $\begin{array}{l}\text { HMA, } \\
50 \% \\
\text { RAP }\end{array}$ & $\begin{array}{l}\text { WMA- } \\
\text { CECABASE }^{\circledR}, \\
50 \% \text { RAP }\end{array}$ & $\begin{array}{l}\text { Foamed } \\
\text { WMA, } \\
50 \% \text { RAP }\end{array}$ \\
\hline \multicolumn{7}{|l|}{ Virgin aggregate } \\
\hline Quantity (\%/m) & 94.4 & 94.4 & 94.4 & 48.4 & 48.37 & 48.36 \\
\hline $\begin{array}{l}\text { Water content } \\
(\% / a)\end{array}$ & 3 & 3 & 3 & 3 & 3 & 3 \\
\hline \multicolumn{7}{|l|}{$R A P$} \\
\hline Quantity (\%/m) & - & - & - & 48.4 & 48.37 & 48.36 \\
\hline $\begin{array}{l}\text { Water content } \\
(\% / \text { RAP })\end{array}$ & - & - & - & 3 & 3 & 3 \\
\hline \multicolumn{7}{|l|}{ Bitumen } \\
\hline Penetration grade & $35 / 50$ & $35 / 50$ & $35 / 50$ & $35 / 50$ & $35 / 50$ & $35 / 50$ \\
\hline Quantity (\%/m) & 5.4 & 5.4 & 5.4 & 3.2 & 3.2 & 3.2 \\
\hline \multicolumn{7}{|l|}{ WMA agent } \\
\hline Type & - & surfactant & water & - & Surfactant & water \\
\hline Quantity $(\% / m)$ & - & 0.054 & 0.077 & - & 0.054 & 0.077 \\
\hline $\begin{array}{l}\text { Mixture density } \\
\left(\mathrm{kg} / \mathrm{m}^{3}\right)\end{array}$ & 2360 & 2340 & 2260 & 2370 & 2360 & 2360 \\
\hline
\end{tabular}

1 Acronyms: HMA- hot mix asphalt; WMA- warm mix asphalt; RAP- reclaimed asphalt pavement; \%/m-

2 percentage by mass of mixture; \%/a- percentage by mass of aggregates; \%/RAP- percentage by mass of RAP.

\subsubsection{Data sources and data quality requirements}

The inventory data required to perform a LCA study are classified into two categories: primary and secondary data. Primary data are those specific to the production processes for the product or service studied in the LCA. In turn, secondary data represent generic or average data for the product or service subject to analysis. (EC, JRC - IES, 2010).

In this study the data sources were selected in order to be as much time, geographical and technological representative as possible. That means that the most recent and truthful data representing French processes and conditions were used as inputs and outputs when modelling the processes covered by the several sub-components integrating the system boundaries. Specifically, the primary data include mainly: (1) the composition of the mixtures; (2) the annual fuel consumption (FC), production and life period of asphalt mix plants; (3) transportation distances; (3) construction vehicles fleet composition; and (4) on-road vehicles fleet composition;

Regarding the secondary data, they are mainly related to the inventory analysis of (1) raw materials, (2) fuels, and (3) construction, transportation, and on-road vehicles operation, and they were obtained from existing publicly available reports and the ecoinvent database version 3.2, but modified whenever possible and suitable to best approximate French conditions by using French energy inputs/mixes.

\subsection{Life cycle inventory}

The life cycle inventory (LCI) stage consists of the real data collection and modelling of the system. In addition to the data sources, it relies on the several models selected for modelling the processes analyzed by the several considered sub-systems that make up the whole system.

\subsubsection{Materials extraction and mixtures production phase}

This pavement LCA phase addresses the environmental burdens arising from the acquisition and processing of the materials applied during the initial construction and future $M \& R$ of a road pavement segment. This includes all materials manufacturing processes, from extraction of raw materials to their transformation into a pavement input material (material extraction sub-phase), ending with the mixture 
1 production at a mixing plant (materials production sub-phase). The latter sub-phase accounts for the environmental burdens associated with the operation of the (1) mixing plant (i.e., dryer, hot screen, mixers, etc.), (2) wheel loader during the movement of aggregates from the stockpiles to the feed bins (3) electronic group of the asphalt plant setup and (4) RAP processing unit so that the RAP ensures the required properties to be incorporated into a new asphalt mixture.

\subsubsection{Materials extraction sub-phase}

The virgin aggregates required to produce the asphalt mixtures were modelled as gravel and the LCI data associated with their production were obtained from the unit process "gravel, crushed | gravel production, crushed" of the ecoinvent database. Also taken from the aforementioned database was the

10 LCI data corresponding to the asphalt binder production "pitch | petroleum refinery operation".

11 Regarding the bituminous emulsion production, the formulation and the consumption of energy resources defined in Eurobitumen report (Eurobitumen, 2011) were considered and combined with the LCI data associated with the production and transport of the corresponding items existing in the ecoinvent database version 3.2.

In one of the WMA production technologies considered in this study, $\mathrm{CECABASE}^{\circledR}$ was used as a chemical additive. According to the scarce information available, this additive is made up of fatty acids, namely tetraethylenepentamine polyamides (http://www.cladding.com.au/Images/common/stakeholder-relations/asphalt-vic/Deer-Park-MSDS-

19 Ceca-RT945.pdf.). Due to the inexistence in the literature of LCI data referring to its production, the ecoinvent database process "market for fatty acid $\mid$ fatty acid $\mid$ cut-off, $U$ " was used as proxy.

As for the RAP processing, the common production rates of the several machines integrating the processing unit were considered when determining the energy requirements. The LCI data related to the production and distribution of those energy resources representing the French conditions were posteriorly taken from the ecoinvent database.

\subsubsection{Mixtures production sub-phase}

This sub-phase addresses the LCI of the asphalt production process by considering different types of mixes, both with and without the incorporation of RAP in their formulations. In this case study it was assumed that all asphalt mixes were produced through a conventional heavy fuel oil (HFO)-fired batch mix plant. The asphalt plant operation takes into account the infrastructure and machinery used in mixes production. The period of life of the plant was estimated to be about 25 years. This value was obtained by considering the average yearly production $(80,000$ tons) and the average life time production $(2,000,000$ tons $)$ of a typical French asphalt plant. The energy required for storing the binder in the asphalt plant, the fuel consumed by the wheel loader and the electricity consumed by the electric group of the asphalt plant were respectively $40 \mathrm{MJ}, 0.194$ liters and $5 \mathrm{MJ}$ per ton of asphalt mix produced and correspond to the average French practices.

In order to capture the consequences in the energy requirements due to the variations in composition and manufacturing temperature of the several types of mixtures as well as the moisture content and initial temperature of the raw materials, the thermal energy (TE) required to produce the asphalt mixtures was determined through an energy balance represented by Equation (1). The values of the parameters in that equation are presented in Table 2 and were based on the literature and conditions commonly found in the real practice. 


$$
T E=\left[\begin{array}{l}
\sum_{i=0}^{M} m_{i} \times C_{i} \times\left(t_{\text {mix }}-t_{0}\right)+m_{\text {bit }} \times C_{b i t} \times\left(t_{\text {mix }}-t_{0}\right)+\sum_{i=0}^{M} m_{i} \times W_{i} \times C_{w} \times\left(100-t_{0}\right) \\
+L_{v} \times \sum_{i=0}^{M} m_{i} \times W_{i}+\sum_{i=0}^{M} m_{i} \times W_{i} \times C_{\text {vap }} \times\left(t_{\text {mix }}-100\right)
\end{array}\right] \times(1+C L)
$$

1

Where $T E$ is the thermal energy (MJ/tonne mixture) required to produce the asphalt mixtures, $m_{i}$ is mass of aggregates of fraction $i, M$ is the total number of aggregates fractions, $C_{i}$ is the specific heat capacity coefficient of aggregates of fraction $i, t_{m i x}$ is the mixing temperature of an asphalt mixture, $t_{o}$ is the ambient temperature, $m_{b i t}$ is the mass of bitumen, $C_{b i t}$ is the specific heat capacity coefficient of bitumen, $W_{i}$ is the water content of aggregates of fraction $i, C_{w}$ is the specific heat capacity coefficient of water, $L_{v}$ is the latent heat required to evaporate water, $C_{v a p}$ is the specific heat capacity coefficient of water vapor, $C L$ is the casing losses factor. Casing losses are thermal energy used to heat plant iron (for example, the shell of the drum) and then radiated to the atmosphere, rather than being used to heat the mixture components (West et al., 2014). This factor was considered to be same for all mixtures studied and was calculated as the difference between the average value of the energy required to produce a conventional HMA in France and that calculated according to the energy balance described above. That means that the unexplained differences in the calculated energy are attributed to casing losses.

Table 2. Values of the parameters considered in Equation (1).

\begin{tabular}{|c|c|c|}
\hline Name & Value & Unit \\
\hline$t_{0}$-Ambient temperature & 15 & ${ }^{\circ} \mathrm{C}$ \\
\hline$t_{H M A, 0 \% R A P}$-Mixing temperature of HMA, $0 \%$ RAP mixture & 160 & ${ }^{\circ} \mathrm{C}$ \\
\hline$t_{H M A, 50 \% R A P}$-Mixing temperature of HMA, 50\% RAP mixture & 160 & ${ }^{\circ} \mathrm{C}$ \\
\hline $\begin{array}{l}t_{W M A-C E C A B A S E, 0 \% R A P} \text {-Mixing temperature of WMA- CECABASE }{ }^{\circledR} \\
0 \% \text { RAP mixture }\end{array}$ & 130 & ${ }^{\circ} \mathrm{C}$ \\
\hline $\begin{array}{l}t_{W M A-C E C A B A S E, 50 \% R A P} \text {-Mixing temperature of WMA- CECABASE }{ }^{\circledR} \text {, } \\
50 \% \text { RAP mixture }\end{array}$ & 130 & ${ }^{\circ} \mathrm{C}$ \\
\hline $\begin{array}{l}t_{\text {foamed } W M A, 0 \% R A P} \text {-Mixing temperature of Foamed WMA, } 0 \% \text { RAP } \\
\text { mixture }\end{array}$ & 130 & ${ }^{\circ} \mathrm{C}$ \\
\hline $\begin{array}{l}t_{\text {foamed WMA, } 50 \% R A P} \text {-Mixing temperature of Foamed WMA, 50\% RAP } \\
\text { mixture }\end{array}$ & 130 & ${ }^{\circ} \mathrm{C}$ \\
\hline $\mathrm{C}_{\mathrm{agg}}$-Specific heat of virgin aggregates ${ }^{\mathrm{a}}$ & 0.74 & $\mathrm{KJ} / \mathrm{Kg} /{ }^{\circ} \mathrm{C}$ \\
\hline $\mathrm{W}_{\mathrm{agg}}$ - Water content of aggregates & 3 & $\%$ by mass of aggregates \\
\hline$C_{R A P 1}$ - specific heat of RAP $^{\mathrm{a}}$ & 0.74 & $\mathrm{KJ} / \mathrm{Kg} /{ }^{\circ} \mathrm{C}$ \\
\hline $\mathrm{C}_{\text {water }}$ - specific heat of water at $15^{\circ} \mathrm{C}$ & 4.1855 & $\mathrm{KJ} / \mathrm{Kg} /{ }^{\circ} \mathrm{C}$ \\
\hline $\mathrm{L}_{\mathrm{v}}$ - latent heat of vaporization of water & 2256 & $\mathrm{~kJ} / \mathrm{kg}$ \\
\hline $\mathrm{C}_{\mathrm{yap}}$ - specific heat of water vapor & 1.83 & $\mathrm{~kJ} / \mathrm{kg}$ \\
\hline $\mathrm{C}_{\text {bit }}$-Specific heat of bitumen & 2.093 & $\mathrm{KJ} / \mathrm{Kg} /{ }^{\circ} \mathrm{C}$ \\
\hline CL- casing loses factor ${ }^{\mathrm{b}}$ & 27 & $\%$ \\
\hline
\end{tabular}

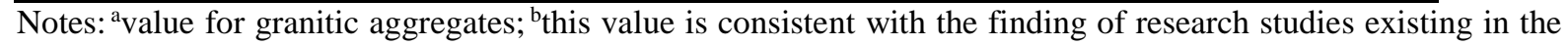
literature (West et al., 2014).

In order to determine the process air emissions resulting from the mixes production, a methodology based on that developed by Santos et al. (2017) was applied. Firstly, the LCI data corresponding to the process "heat production, heavy fuel oil, at industrial furnace $1 M W \mid$ heat, district or industrial, other than natural gas $\mid$ cut-off, $U$ " existing in the ecoinvent database was taken as reference when modeling the operation of the burner existing in the asphalt plant during the production of a conventional HMA 
with 0\% RAP. Secondly, for the remaining mixes an emission factor (EF) multiplier was determined through the ratio between the thermal energy computed with Equation (1) for those mixes and that for the reference mix. Finally, the output flows expressed in terms of the GHG and the most common airborne substances released during mixes production were derived by multiplying the outputs flows taken as reference by the EF multipliers. The values of the EF multipliers as well as the thermal energy required to produce 1 ton of the mixtures studied are shown in Table 3. The fuel savings presented in this table are consistent with those commonly reported in the literature for both European (D'Angelo et al., 2008) and US (Mohammad et al., 2014) practices, according to which the reduction of the fuel consumption might amount to $11-35 \%$ and $12-14 \%$, respectively, the latter expressed in terms of fuel costs. These ranges of values support the validity of the thermal energy model developed.

Table 3. Thermal energy (TE) required to produce 1 tonne of the mixtures studied and respective emission factor $(\mathrm{EF})$ multipliers.

\begin{tabular}{|c|c|c|c|c|c|c|}
\hline & \multicolumn{6}{|c|}{ Type of mixture } \\
\hline & $\begin{array}{l}\text { HMA, } 0 \% \\
\text { RAP }\end{array}$ & $\begin{array}{l}\text { WMA- } \\
\text { CECABASE }^{\circledR} \text {, } \\
0 \% \text { RAP }\end{array}$ & $\begin{array}{l}\text { Foamed } \\
\text { WMA, 0\% } \\
\text { RAP }\end{array}$ & $\begin{array}{l}\text { HMA, } 50 \% \\
\text { RAP }\end{array}$ & $\begin{array}{l}\text { WMA- } \\
\text { CECABASE®, } \\
50 \% \text { RAP }\end{array}$ & $\begin{array}{l}\text { Foamed } \\
\text { WMA, 50\% } \\
\text { RAP }\end{array}$ \\
\hline $\begin{array}{l}\text { TE }(\mathrm{MJ} / \text { tonne } \\
\text { mixture) }\end{array}$ & 255 & 226 & 226 & 251 & 222 & 222 \\
\hline $\begin{array}{l}\mathrm{TE}(\mathrm{Kg} \mathrm{HFO} / \text { tonne } \\
\text { mixture) }\end{array}$ & 6.05 & 5.35 & 5.35 & 5.96 & 5.26 & 5.26 \\
\hline $\mathrm{EF}(\%)$ & - & 89 & 89 & 99 & 87 & 87 \\
\hline
\end{tabular}

Acronyms: TE- thermal energy; HFO- heavy fuel oil. Notes: Lower Heating Value of HFO was considered to be equal to $42.18 \mathrm{MJ} / \mathrm{Kg}$ (IEA, 2005).

\subsubsection{Construction and $M \& R$ phase}

In the construction and M\&R phase, the environmental burdens are due to the combustion-related emissions from construction machinery usage. Environmental impacts resulting from traffic congestion occurring during $M \& R$ interventions are dealt with in the WZ traffic management phase. The consumption-related emissions associated with the operation of each construction equipment were determined by combining the LCI data corresponding to the ecoinvent database process "machine operation, diesel, $>=74.57 \mathrm{~kW}$, high load factor $\mid$ machine operation, diesel, > $=74.57 \mathrm{~kW}$, high load factor" with the typical productivity of each operation involved in pavement construction and maintenance activities.

In this section it is worth mentioning that the operating conditions of paving machines were considered the same regardless of the type of asphalt mix considered, i.e. HMA or WMA (with and without). Theoretically, a reduction in the number of roller passes needed to achieve a specified density is expected when WMA is used (Rubio et al., 2012; Zaumanis, 2014). However, there is no accurate and consistent scientific knowledge in the literature on the close relation between the reduction of the compactive effort required, in terms of roller passes, and the enhancement of WMA workability.

\subsubsection{Transportation of materials phase}

The environmental impacts resulting from the transportation of materials are due to the emissions released during the combustion process of the transportation vehicles when performing two-way trips. All materials and mixtures were assumed to be hauled by HDV, and a modified version of the ecoinvent database process "transport, freight, lorry >32 metric ton, EURO4| transport, freight, lorry >32 metric ton, EURO4 | cut-off, $U$ " was used to determine the environmental burdens associated with the transportation of materials movements. The original process was modified in order to disregard the inventory corresponding to the construction of the road infrastructure that is considered by the original 
process. The transportation distances considered for each material and mixture used in this case study are representative of the French conditions and are shown in Table 4.

Table 4. Transportation distances considered in the case study.

\begin{tabular}{ll}
\hline Type of material & One-way trip distance $(\mathrm{km})$ \\
\hline Aggregates & 20 \\
RAP & 20 \\
Binder and bitumen emulsion & 100 \\
Asphalt mixtures & 20 \\
Emulsifer & 500 \\
Hydrochloric acid $^{\mathrm{a}}$ & 500 \\
CECABASE $^{\circledR}$ additive $^{2}$ & 50 \\
\hline
\end{tabular}

\subsubsection{Work-zone traffic management phase}

This pavement life cycle phase accounts for the marginal FC and emissions released by on-road vehicles due to traffic perturbations caused by $M \& R$ events in relation to those during normal road operation. The procedure adopted to calculate the environmental burdens arising during this phase was based on the two-step methodology developed by Santos et al. (2015a, 2015b).

First, the COPERTv5.0 air pollutants and GHG emissions model (EMISIA, 2017) was run multiple times, each considering a different speed in the "Highway" driving mode, to compute a set of FC and emissions factors representing the French vehicle fleet characteristics per type of vehicle. Next, the FC and vehicle emissions calculated for the several discrete speed values are used to derive equations that allow to determine FC and emissions factors representative of the French vehicle fleet as a continuous function of the speed.

Secondly, changes in driving patterns were modelled using the capacity and delay models proposed by the HCM 2000 (TRB, 2000) to determine several outputs, such as the number of vehicles that traversed the WZ, the average queue length, the average queue speed in each hour, etc. Each section where there is a change in driving pattern was considered to be a new road "link". The characteristics of each link (length, number of vehicles and average speed) was combined with the equations previously determined to derive the environmental load of a WZ hour of a given M\&R activity. Finally, the marginal FC and airborne emissions due to the WZ traffic management plan were calculated by subtracting FC and airborne emissions released during a WZ period from the results of an equivalent non-WZ period.

\subsubsection{Usage phase}

The usage phase addresses the pavement's environmental burden resulting from the interaction of the pavement with the vehicles, environment and humans throughout its PAP. Among the factors that have been identified in past research as being worthy of consideration during the usage phase of the pavement (i.e., pavement-vehicle interaction (PVI), traffic flow, albedo, leachate and runoff, carbonation and lighting) only the contribution from the PVI, namely that due to the pavement surface properties (i.e., macrotexture and pavement roughness), was taken into account in this analysis. The rationale for this decision lies in the fact that the remaining components either do not apply to the features of the case study under evaluation or lack well established and consistent scientific background. In order to determine the influence of the pavement surface properties on vehicle FC and tailpipe emissions, the Swedish National Road and Transport Research Institute (VTI)'s rolling resistance (RR) model (Hammarström et al., 2012), developed within the European project MIRIAM (Models for rolling resistance In Road Infrastructure Asset Management systems), was combined with data from the 
1 COPERTv5.0 emissions model according to the two-step methodology proposed by Santos et al. 2 (2015a).

In the first step, the VTI's RR model was used to calculate the additional FC due to the vehicles travelling over the rough pavement surface when compared to the FC of the vehicles travelling over a smooth surface. Then, instead of using the actual AADT in the COPERTv5.0 emissions model, an effective AADT $\left(\mathrm{AADT}_{\mathrm{E}}\right.$ ) was used to relate the effect of pavement surface properties on the $\mathrm{FC}$ and emissions. The $\mathrm{AADT}_{\mathrm{E}}$ for a given macrotexture and roughness at time $t$, expressed in terms of the mean profile depth (MPD) and international roughness index (IRI), respectively, was calculated using Equation (2).

$$
A A D T_{E}(t)=A A D T(t) \times \sum_{i=0}^{N-V e h} V e h_{i} \times \frac{F C_{i}^{I R I(t), M P D(t)}}{F C_{i}^{\text {smooth }}}
$$

Where AADT is the annual average daily traffic value, $N_{-}$Veh is the number of types of vehicles (in this case study it is equal to three, corresponding to passenger cars, rigid HDV and articulated HDV), $V e h_{i}$ is the percentage of vehicles of type $i$ in the AADT, $F C_{i}^{\operatorname{IRI}(t), M P D(t)}$ is the FC for the type of vehicle $i$ travelling on a pavement with a specified IRI and MPD at time $t$, and $F C_{i}^{\text {smooth }}$ is the FC of the same type of vehicle $i$ travelling along a typical smooth pavement.

Estimating the influence of RR on FC and tailpipe emissions requires the prediction of the progression of the pavement surface properties over the PAP. In this case study, the pavement performance prediction model of the flexible pavement design method developed by AASHTO (1993) was adopted to predict the quality of the pavement over time, expressed in terms of PSI (Equation (3)). This model was posteriorly combined with the expression proposed by Al-Omari and Darter (1994) to convert the PSI into IRI (Equation (4)). From the conceptual point of view, such conversion does not seem to represent an obstacle, as roughness is widely recognized as the main contributor to PSI. In turn, the model proposed by Lorino et al. (2008) was adopted to predict the evolution of the macrotexture over the PAP (Equation (5)).

$$
\begin{aligned}
& P S I_{t}=P S I_{0}-(4.2-2) \times 10^{\left[\left(\log _{10}\left(W_{80_{t}}\right)-Z_{R} \times S_{0}-9.36 \log _{10}\left(S N_{t}+1\right)+0.2-2.3 \times \log _{10}\left(M_{R}\right)+8.07\right) \times\left(0.4+\frac{1094}{\left(S N_{t}+1\right)^{5.19}}\right)\right]} \\
& I R I_{t}=-\frac{1}{0.24} \times \operatorname{Ln}\left(\frac{P S I_{t}}{5}\right) \\
& M P D_{t}=0.986-0.168 \times \ln (\text { age })
\end{aligned}
$$

Where $P S I_{t}$ is the Present Serviceability Index in year $t, P S I_{0}$ is the Present Serviceability Index of a pavement immediately after construction (year 0 ), $W_{80_{t}}$ is the number of $80 \mathrm{kN}$ equivalent single axle load (ESAL) applications in year $t$ (million ESAL/lane), $Z_{R}$ is the standard normal deviate, $S_{0}$ is the combined standard error of the traffic prediction and performance prediction, $S N_{t}$ is the structural number of a pavement structure in year $t, M_{R}$ is the sub-grade resilient modulus (pounds per square inch), $I R I_{t}$ is the International Roughness Index $(\mathrm{m} / \mathrm{km}), M P D_{t}$ is the mean profile depth $(\mathrm{mm})$, age is the age of the surface course (years). In this case study the following parameters values were considered: a $Z_{R}$ value of -1.282 , a $S_{0}$ value of 0.45 and a $S N_{0}$ value of 5.13. 


\subsubsection{End-of-life phase}

When a road pavement reaches the end of the PAP, it can be given two main destinations: (1) remain in place, or; (2) be removed. In this case study, it is assumed that the pavement remains in place and undergoes the M\&R activity illustrated in Figure 2. The environmental burdens assigned to this phase are due to the materials extraction and mixtures production and the combustion-related emissions from the use of the construction equipment and transportation HDV. The environmental impacts resulting from the traffic disruption occurring during the EOL intervention are dealt with in the WZ traffic management phase.

\subsection{Life Cycle Impact assessment}

The life cycle impact assessment (LCIA) stage of the standardized LCA methodology comprises several steps, namely, classification, characterization, normalization, group and weighting (ISO, 2006a). Among these steps, only classification and characterization were undertaken in this study. The normalization, group and weighting are optional, and while they might be useful in translating the impact scores of different impact categories into a more understandable and somehow digestible form (Dahlbo et al., 2013), they also entail a risk of oversimplifying the results. Furthermore, in accordance with ISO 14040 series (ISO, 2006a; ISO, 2006b) no form of numerical, value-based weighting of the indicator results is permitted to be published, if the study is intended to support a comparative assessment to be disclosed to the public.

The calculation of the impact category indicator scores was performed at midpoint level by applying mainly the LCIA method CML 2001 (Guinée et al., 2002). This method was selected because it is the primary base for the construction of the French environmental standards on building construction materials, the NF P 01-010 standard (AFNOR \& French Standardisation Agency, 2004). Specifically, the following impact categories were considered: Climate Change (CC), Acidification (AC), Eutrophication (EU), Human toxicity (HT), Terrestrial ecotoxicity (TE), Photochemical oxidation (PO), Stratospheric ozone layer depletion (SOD), Abiotic resources depletion (ARD). Complementarily, the ReCiPe method's impact categories Particulate matter formation (PM) and Water depletion (WD) were also considered (Goedkoop et al., 2013). A time horizon of 100 years was considered for all impacts categories.

In addition, an energy analysis was carried out based on the cumulative energy demand (CED) indicator, computed according to Frischknecht et al. (2007).

Finally, the OpenLCA software version 1.5.0 was used for modelling the processes analyzed in this case study (GreenDelta, 2016).

\section{Results and discussion}

\subsection{Baseline scenario}

\subsubsection{Total pavement life cycle impacts assessment results}

The comparison between the environmental and energy indicators scores of the six pavement construction and $M \& R$ alternatives are illustrated in Figure 3. Table 1 in supplementary materials present their values. Based on LCIA results, one can say that a pavement construction and M\&R scenario in which the mixture Foamed WMA, 50\%RAP is employed in the wearing course throughout the pavement life cycle is the most environmentally friendly alternative among all the competing solutions, as it was found to present the best environmental performance in all environmental and energy indicators. For instance, for $\mathrm{CC}$ its overall impact score totals $1178377 \mathrm{~kg} \mathrm{CO}_{2}$-eq, for $\mathrm{AC} 9630 \mathrm{SO}_{2^{-}}$ eq, for HT $600713 \mathrm{~kg}$ 1.4-DCB-eq, for PO $543 \mathrm{~kg}$ ethylene-eq, and for ARD $27452 \mathrm{~kg}$ antimony-eq. These values mean a reduction of $6 \%, 7 \%, 5 \%, 8 \%$ and $9 \%$, respectively, in relation to the impact scores associated with the use of the mixture HMA, $0 \%$ RAP. 
Indeed, the use of the mixture HMA, 0\%RAP in the wearing course of a pavement throughout its life cycle is, in general, the most environmentally damaging alternative among all the competing solutions, as it was found to exhibit the worst environmental performance in 9 of the 12 environmental and energy indicators. The exceptions to the " 12 of the 12 " were observed for the impact categories TE, WD and renewable CED in which the alternative WMA- CECABASE $^{\circledR}, 0 \%$ RAP denoted the most expressive scores (i.e. $2035 \mathrm{~kg}$ 1.4-DCB-eq, $4123 \mathrm{~m}^{3}$ and $625501 \mathrm{MJ}$ ), followed by its recycling-based counterpart, i.e. the mixture WMA- CECABASE ${ }^{\circledR}, 50 \%$ RAP with impact scores equal to $2016 \mathrm{~kg} 1.4-$ DCB-eq, $3936 \mathrm{~m}^{3}$ and $591512 \mathrm{MJ}$, respectively. Such results, which in the case of the mixture WMACECABASE $^{\circledR}, 0 \%$ RAP represent an increase of $233 \%, 70 \%$ and $19 \%$ relatively to those of the mixture 10 HMA, 0\%RAP, are explained by the process "market for fatty acid $\mid$ fatty acid $\mid$ cut-off, $S$ - GLO", which with contributions greater than $71 \%$ and $41 \%$, respectively for the impact categories TE and WD, was found to be main driver of such categories. Also, it was the responsible for the notorious consumption of biomass energy that is the root cause of the greater consumption of renewable energy. Similar contributions were found in the case of its recycling-based counterpart (i.e., the mixture WMA$\left.\mathrm{CECABASE}^{\circledR}, 50 \% \mathrm{RAP}\right)$.

On comparing pavement construction and $M \& R$ alternatives employing in the wearing course HMA or WMA mixtures without the addition of RAP, it was observed that the overall life cycle impacts of the alternatives using WMA mixtures were, in general, reduced by no more than $2 \%$ (WMACECABASE $^{\circledR}, 0 \%$ RAP) and 3\% (Foamed WMA, 0\%RAP). These tiny benefits agree well with the findings reported by Vidal et al. (2013), although the type of WMA analysed in that study was different from those considered in the present study.

In addition, when comparing mixtures with a null content of RAP with their recycling counterpart (i.e. 50\% RAP), it was observed that the life cycle environmental benefits mentioned above rose to values that can be as high as 9\%. That is the case of the mixtures HMA, 50\%RAP and WMA$\mathrm{CECABASE}^{\circledR}, 50 \%$ RAP for the impact categories ARD and SOD. Indeed, for those impact categories all the mixtures that do not contain RAP and those that contain RAP denote similar scores. In turn, the lowest life cycle environmental benefits are registered by the mixtures WMA- CECABASE ${ }^{\circledR}, 50 \%$ RAP and Foamed WMA, 50\%RAP for the impact category TE (1\% and 2\%, respectively).

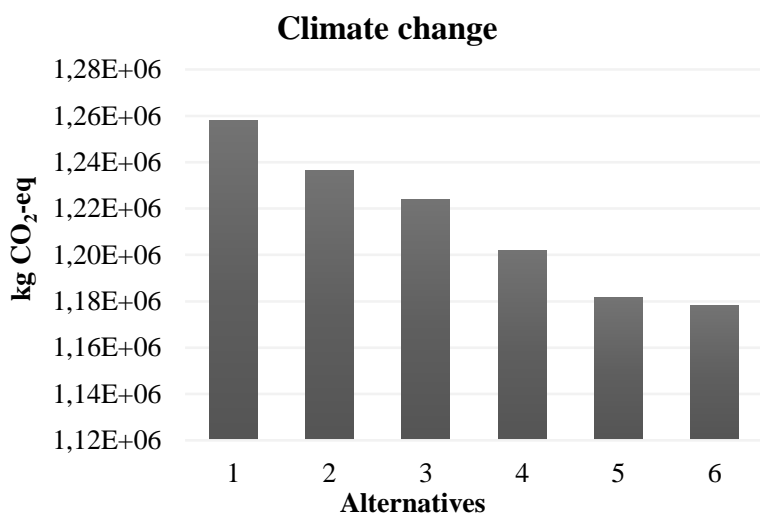

(a)

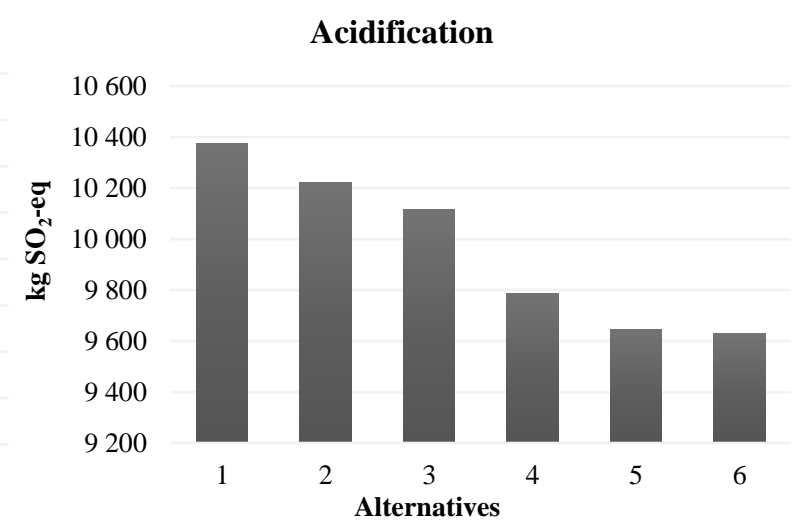

(b) 


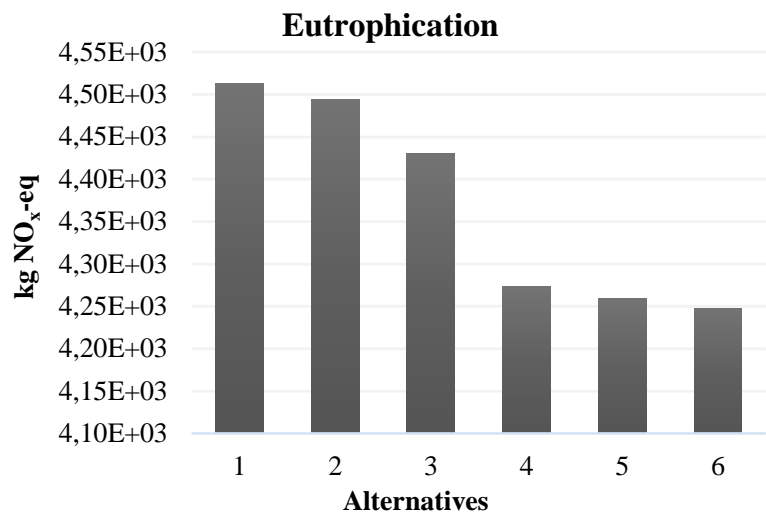

(c)

Terrestrial ecotoxicity

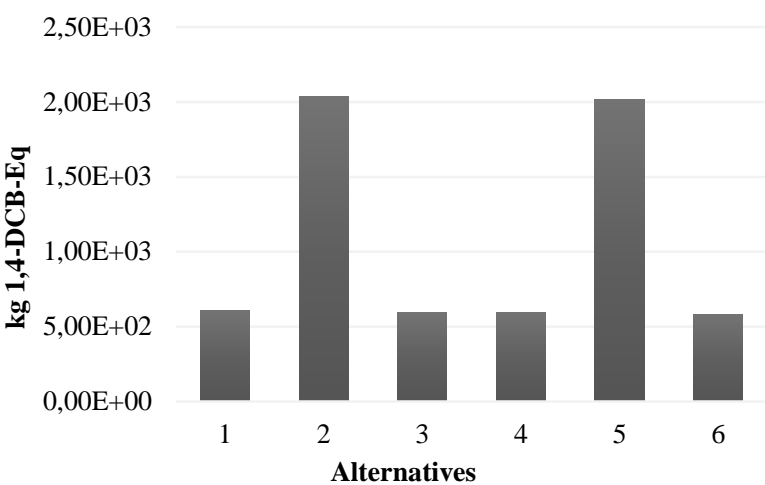

(e)

Stratospheric ozone depletion

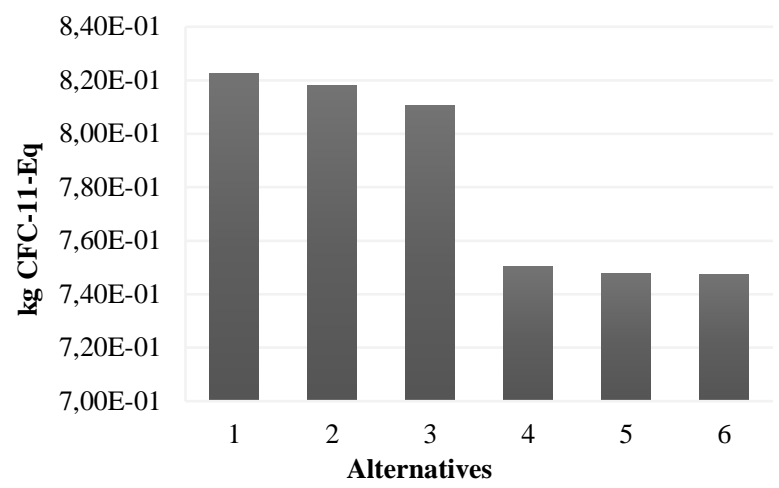

(g)

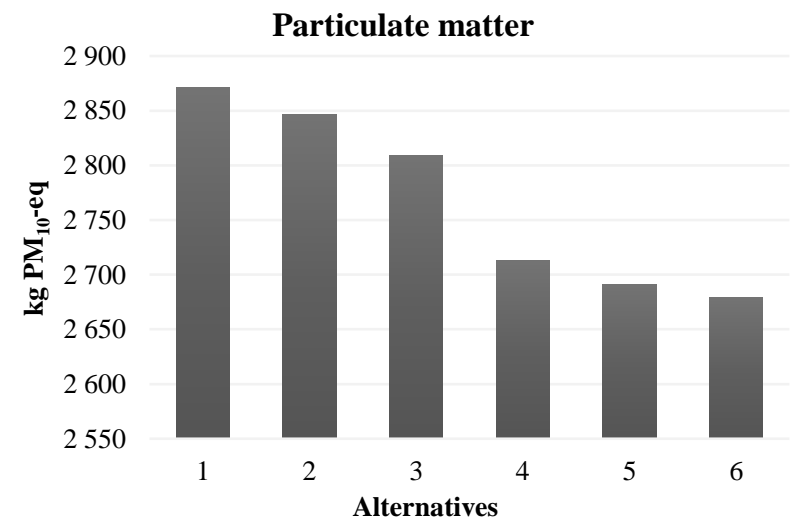

(i)

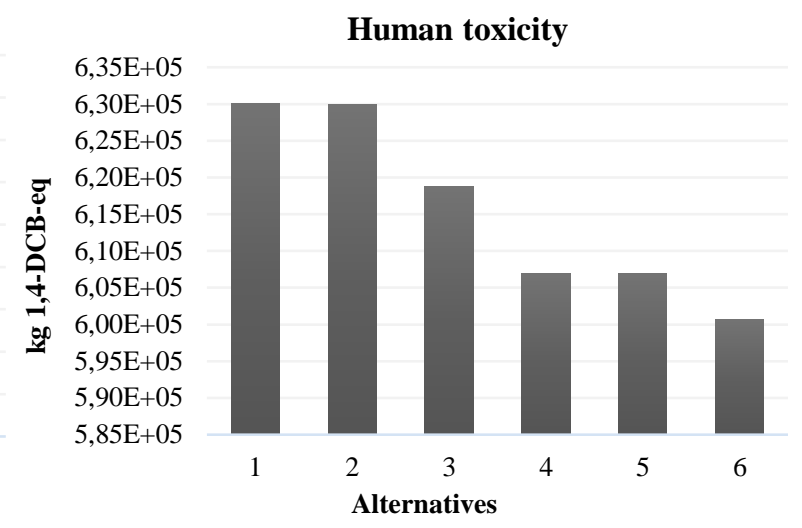

(d)

Photochemical oxidation

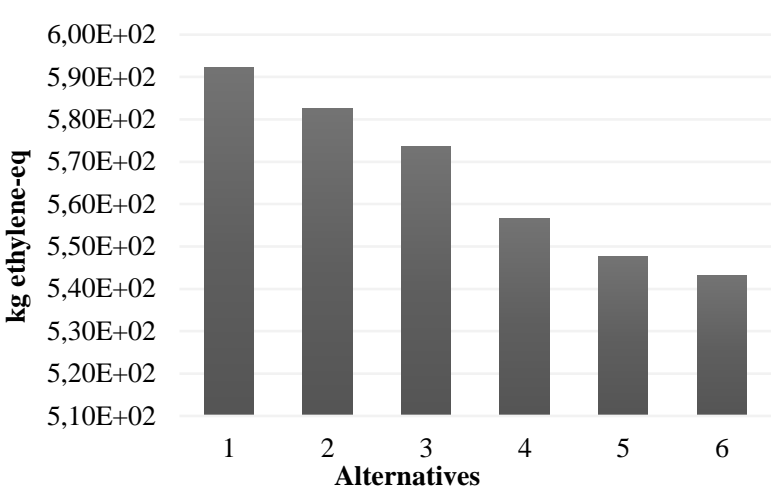

(f)

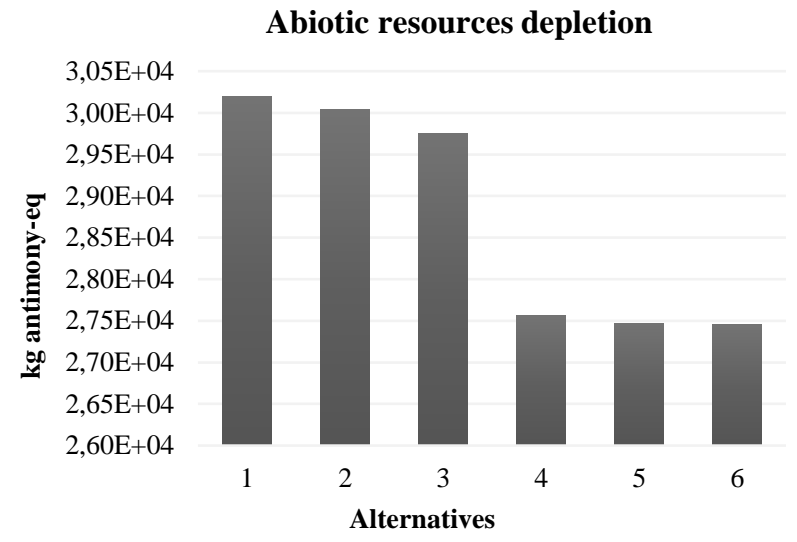

(h)

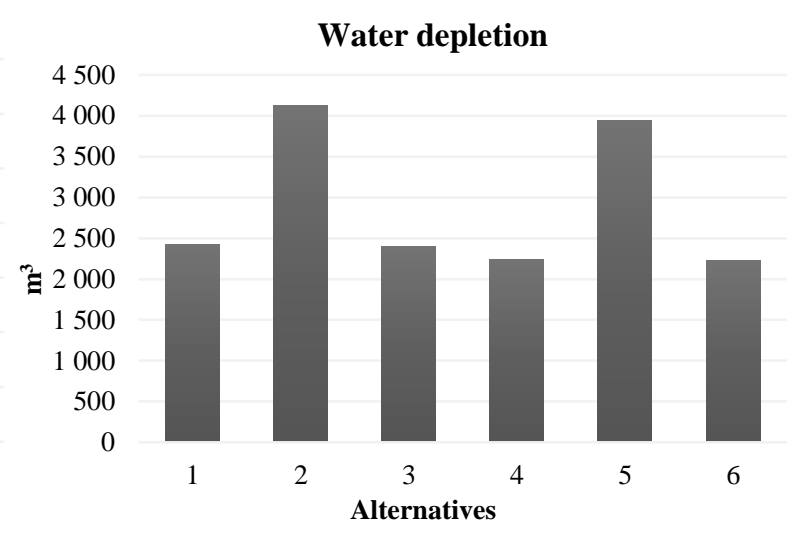

(j) 


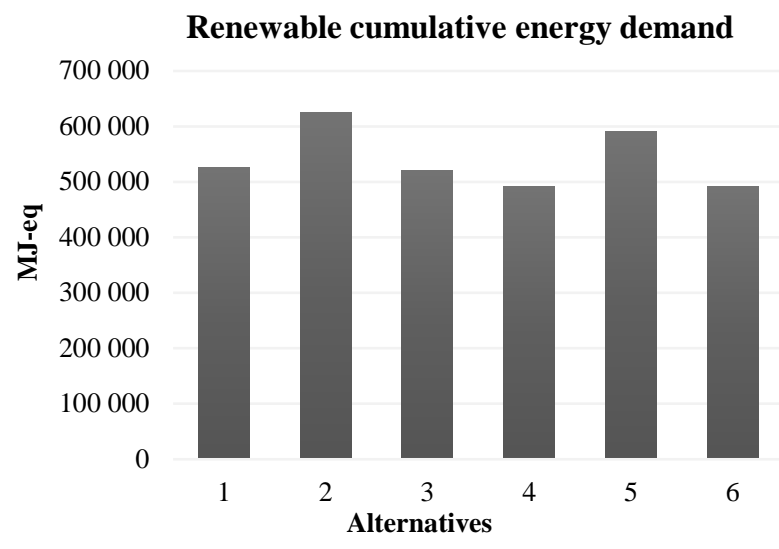

(k)

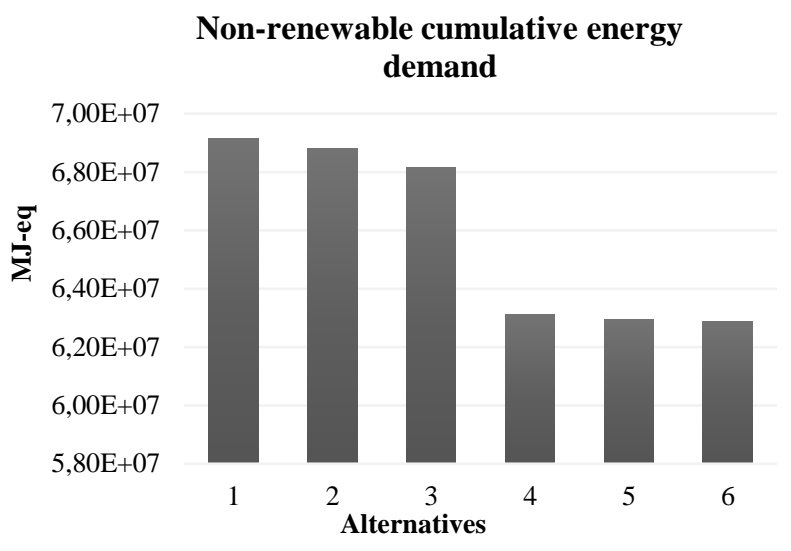

(1)

1 Figure 3. Life cycle impact assessment results. Key: Alternative 1: HMA, 0\%RAP; Alternative 2: WMA2 CECABASE ${ }^{\circledR}$, 0\%RAP; Alternative 3: Foamed WMA, 0\%RAP; Alternative 4: HMA, 50\%RAP;

3 Alternative 5: WMA- CECABASE ${ }^{\circledR}, 50 \%$ RAP; Alternative 6: Foamed WMA, 50\% RAP.

\subsubsection{Process contribution analysis}

Figure 4 displays the contribution of the processes to the impact categories considered for all alternatives being compared. Overall, the environmental impacts are driven predominantly by the processes bitumen production and asphalt mixtures manufacturing. This general pattern is observed not only for all impact categories but also across all the alternatives. The share of the process bitumen production can be as high as $83 \%$ (SOD score for the alternatives WMA- CECABASE ${ }^{\circledR}, 0 \%$ RAP and Foamed WMA, $0 \%$ RAP), whereas the highest contribution given by the asphalt mixtures manufacturing (around 57\%) is observed in the impact category TE for the alternative conventional HMA, 0\%RAP. The market for asphalt mixing plant and gravel production are other processes whose contributions cannot be neglected, although their maximum share does not go beyond 35\% (HT score for the alternative conventional HMA, 0\%RAP) and 25\% (WD score for the alternative Foamed WMA, $0 \%$ RAP), respectively. In turn, the contributions of the transportation of materials and construction machinery operation are relatively reduced, under 7\% (EU score for the alternatives conventional HMA, 0\%RAP, WMA- CECABASE ${ }^{\circledR}, 0 \%$ RAP, Foamed WMA, 0\% RAP and WMA- CECABASE $^{\circledR}, 50 \%$ RAP) and $8 \%$ (EU score for the alternative WMA- CECABASE ${ }^{\circledR}, 50 \%$ RAP), respectively.

Finally, it is worth mentioning that the length of the bars corresponding to the mixtures WMACECABASE $^{\circledR}, 0 \%$ RAP and WMA- CECABASE $^{\circledR}, 50 \%$ RAP for the impact categories TE and WD prove what was said in the previous section regarding the preponderance of the contribution given by the process "market for fatty acid | fatty acid | cut-off, S - GLO" for the scores of those impact categories.
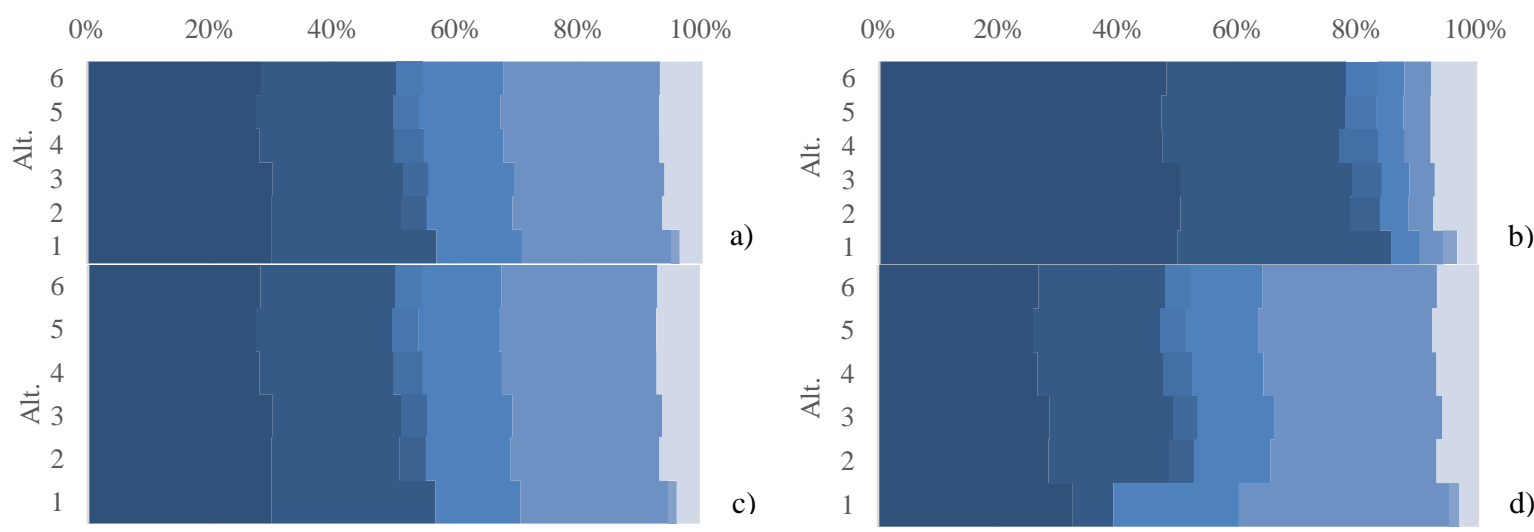

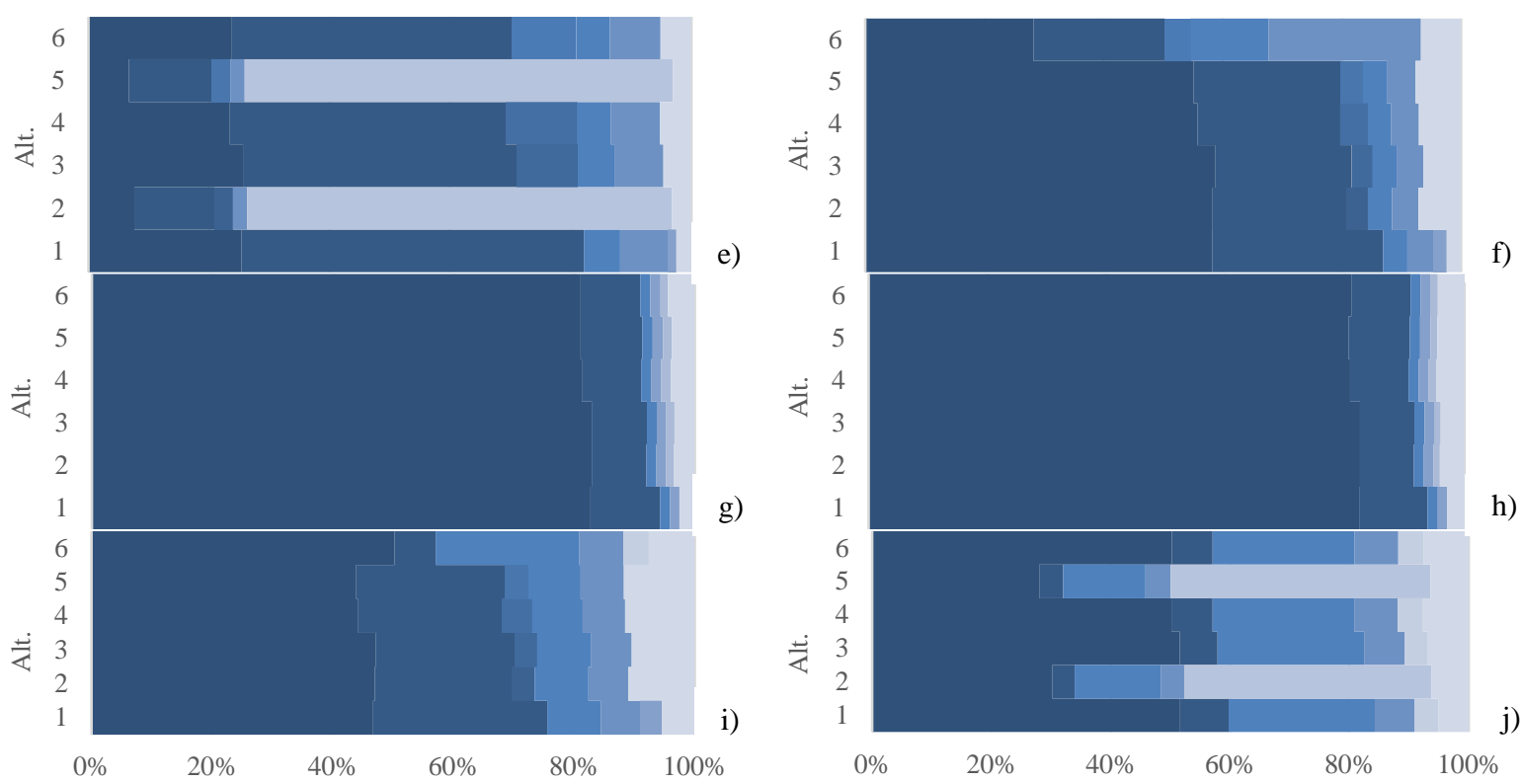

- petroleum refinery operation | pitch | cut-off, S - Europe without Switzerland

- conventional HMA production- heat production, heavy fuel oil, at industrial furnace 1MW | heat, district or industrial, other than natural gas | cut-off, S - Europe without Switzerland

- WMA- CECABASE, 0\%RAP production - heat production, heavy fuel oil, at industrial furnace 1MW | heat, district or

industrial, other than natural gas | cut-off, U - Europe without Switzerland
- foamed WMA, $0 \%$ RAP production- heat production, heavy fuel oil, at industrial furnace 1MW | heat, district or industrial,

other than natural gas | cut-off, U - Europe without Switzerland

- HMA, 50\%RAP production - heat production, heavy fuel oil, at industrial furnace $1 \mathrm{MW} \mid$ heat, district or industrial, other than natural gas | cut-off, U - Europe without Switzerland

- WMA- CECABASE, 50\%RAP production - heat production, heavy fuel oil, at industrial furnace 1MW | heat, district or

industrial, other than natural gas | cut-off, U - Europe without Switzerland

- foamed WMA, 50\%RAP production- heat production, heavy fuel oil, at industrial furnace $1 \mathrm{MW} \mid$ heat, district or industrial,

other than natural gas $\mid$ cut-off, U - Europe without Switzerland
gravel production, crushed $\mid$ gravel, crushed $\mid$ cut-off, S - CH

narket for concrete mixing factory $\mid$ concrete mixing factory $\mid$ cut-off, S - GLO

- machine operation, diesel, >=74.57 kW, high load factor $\mid$ machine operation, diesel, >=74.57 kW, high load factor $\mid$ cutoff, S - GLO

transport, freight, lorry >32 metric ton, EURO4 | transport, freight, lorry >32 metric ton, EURO4 | cut-off, U (excluding

road construction) - RER

- petroleum and gas production, on-shore | petroleum | cut-off, U - RoW

$\square$ market for fatty acid | fatty acid | cut-off, S - GLO

market for electricity, medium voltage | electricity, medium voltage | cut-off, S - FR

others

Figure 4. Contribution analysis by process: a) climate change; b) acidification; c) eutrophication; d) human toxicity; e) terrestrial ecotoxicity; f) photochemical oxidation; g) stratospheric ozone depletion; h) abiotic resources depletion; i)- particulate matter; j) water depletion. Key: Alternative 1: HMA, 0\%RAP; Alternative 2: WMA- CECABASE ${ }^{\circledR}$, 0\%RAP; Alternative 3: Foamed WMA, 0\%RAP; Alternative 4: HMA, 50\% RAP; Alternative 5: WMA- CECABASE ${ }^{\circledR}$, 50\% RAP; Alternative 6: Foamed WMA, 50\% RAP.

\subsubsection{Pavement life cycle phase contribution analysis}

Figure 5 presents the contribution of each of the pavement life cycle phases to the 12 impact and energy indicators considered and for each of the pavement construction and M\&R alternatives studied. The environmental performance of all alternatives for almost all impact and energy indicators are mainly driven by the phases related to the construction of the initial pavement structure, which comprises the materials extraction and production, the construction machinery operation and the transportation of the materials and mixtures. Its share varies between $29 \%$ and $57 \%$ for the indicator TE. The exception to the construction phase's dominance is observed in the TE indicator for the alternatives WMA- $\mathrm{CECABASE}^{\circledR}, 0 \%$ RAP and WMA- $\mathrm{CECABASE}^{\circledR}, 50 \%$ RAP, where the maintenance phase is the main contributor. The root cause of this outcome is the preponderance of the 
process "market for fatty acid $\mid$ fatty acid $\mid$ cut-off, $S$ - GLO" in driving the environmental burdens of those alternatives with respect to the impact categories TE and WD, along with the fact that the total mass of those mixtures applied in all maintenance activities performed throughout the pavement life cycle is greater than that employed in the construction of the initial pavement structure. If the TE and WD indicators were not taken into account, then the construction phase would always be the main contributor for the remaining indicators with a minimum share not inferior to $49 \%$, followed by the maintenance and EOL phases.

Another noteworthy result emerging from the analysis of Figure 5 pertains to the almost consensual residual contribution given by the WZ traffic management and usage phases to all impact and energy indicators. Furthermore, in the usage phase the relative contributions are not only approximately $0 \%$, but also negative, meaning that this phase plays a beneficial role for the environment. In the case of the WZ traffic management phase such outcome is entirely explained by the reduced traffic value carried by the road pavement throughout its life cycle, which is not enough to originate congestion when an $M \& R$ intervention is performed. As far as the usage phase is concerned, in addition to the low traffic volume, the explanation also lays on the way the pavement roughness and macrotexture impact RR and how such pavement surface properties evolve over time. In the VTI's RR model, while an increase of pavement roughness and macrotexture leads to an increase of the RR, and thus the vehicle's fuel consumption, the absolute effect of macrotexture is, in general, greater than that of roughness (Bryce et al., 2014). Given that in this case study the pavement macrotexture is expected to decrease over time according to Lorino et al.'s model, its effect offset that of the roughness, notwithstanding the fact that the value of latter property is expected to increase throughout the pavement life cycle. Therefore, due to the combined effects of the aforementioned surface properties on vehicle's fuel economy and their evolution over the PAP, the usage phase turns out to be environmentally advantageous.

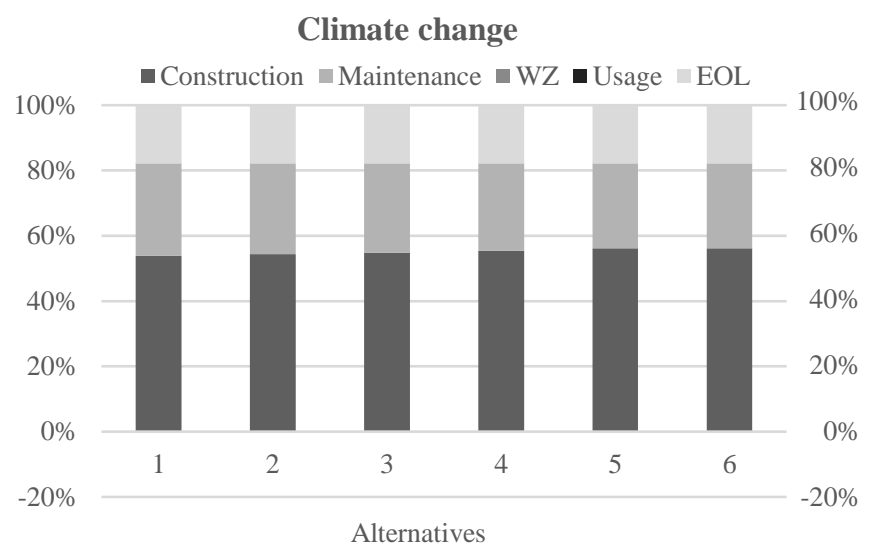

(a)

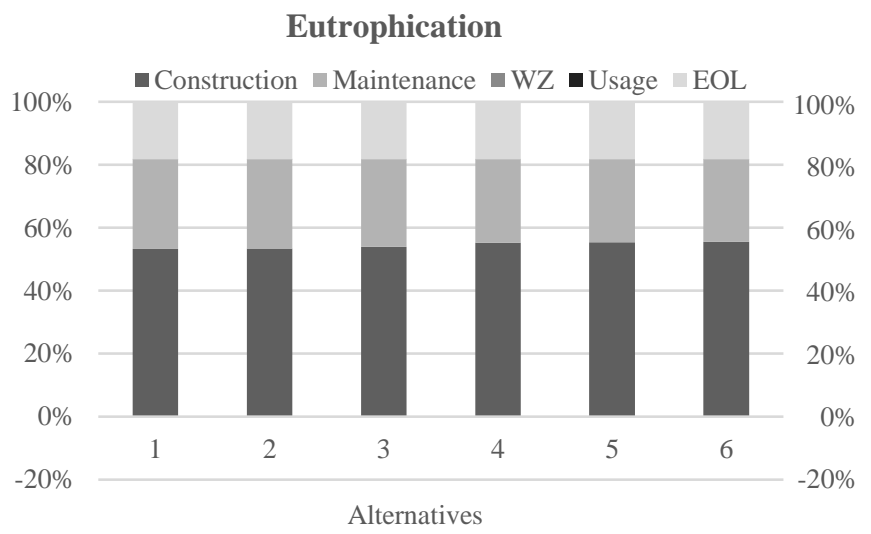

(c)
Acidification

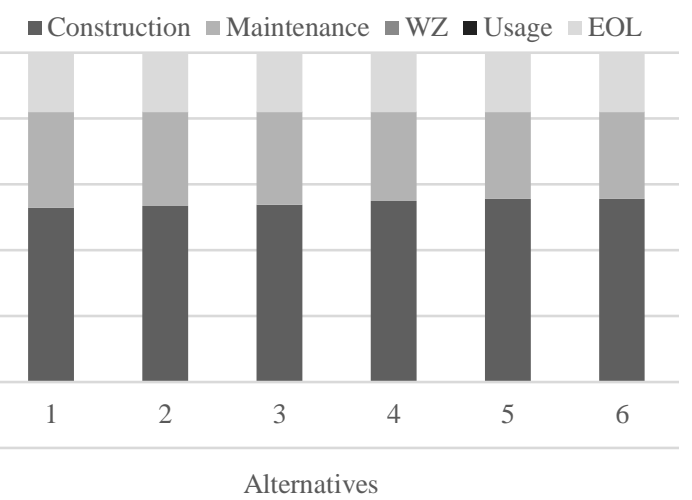

(b)

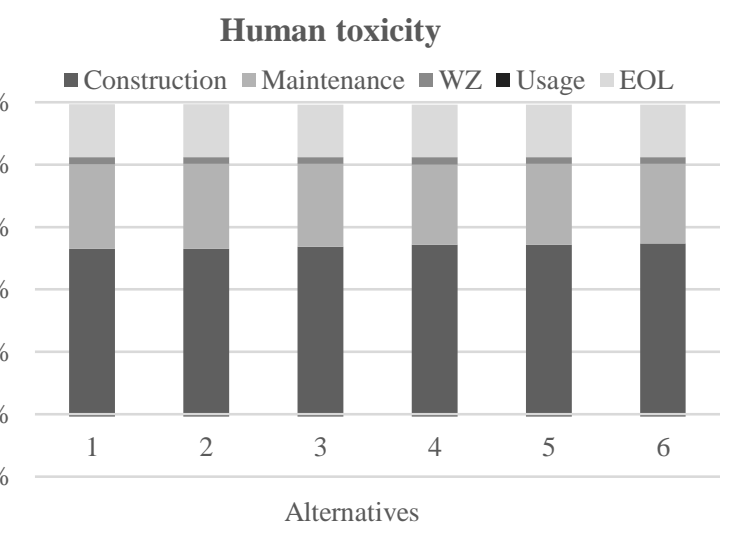

(d) 
Terrestrial ecotoxicity

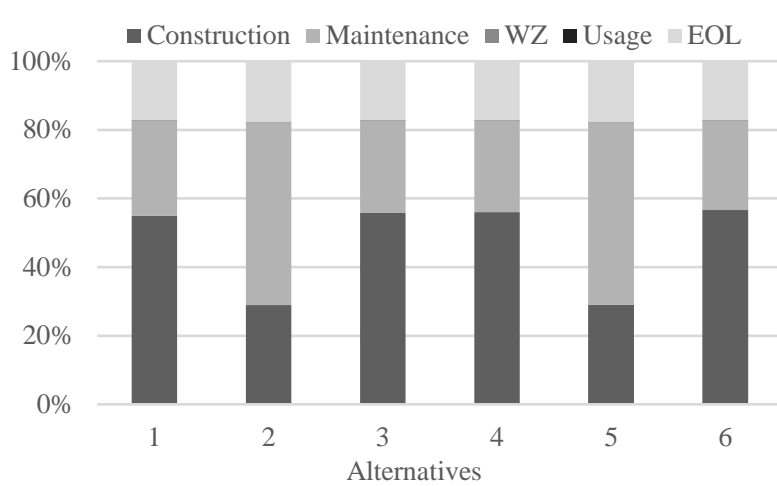

(e)

Stratospheric ozone depletion

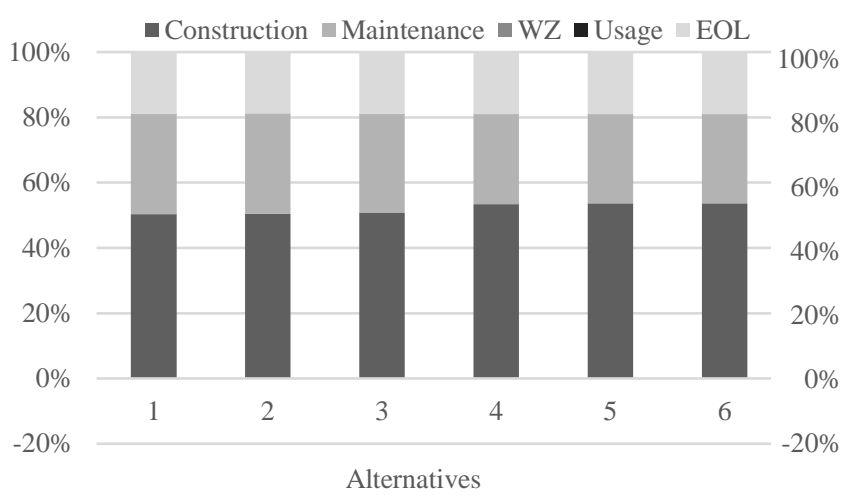

(g)

Particulate matter

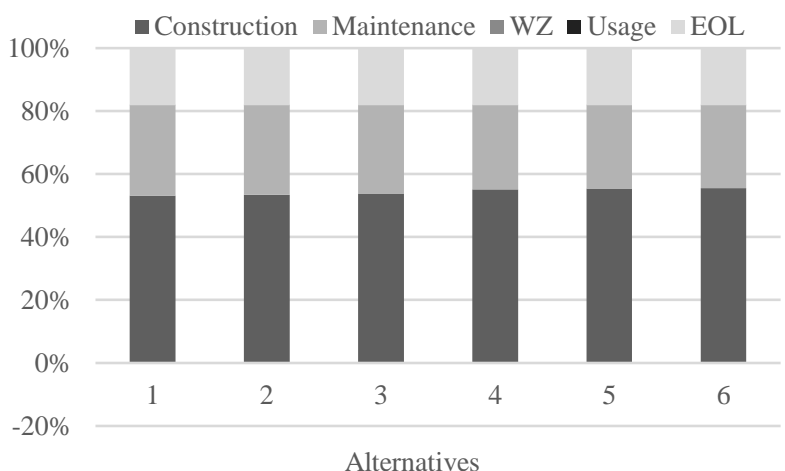

(i)

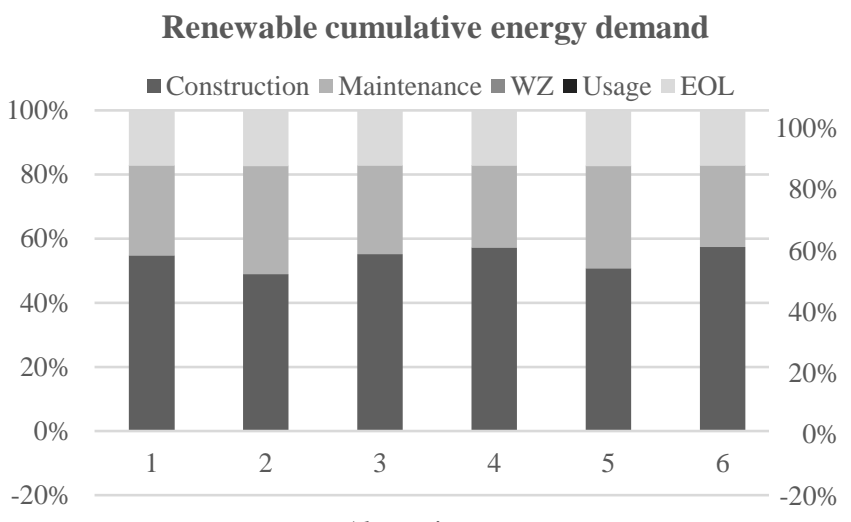

Alternatives

(k)
Photochemical oxidation

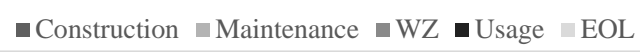

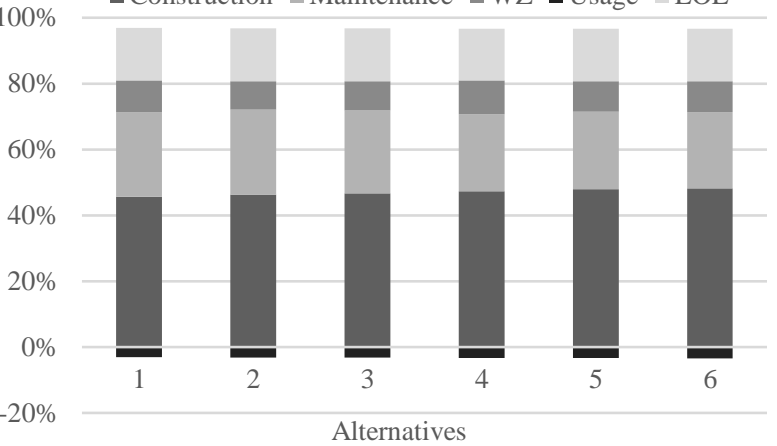

(f)

Abiotic resources depletion

-Construction $\square$ Maintenance $\square \mathrm{WZ} \backsim$ Usage $\square$ EOL

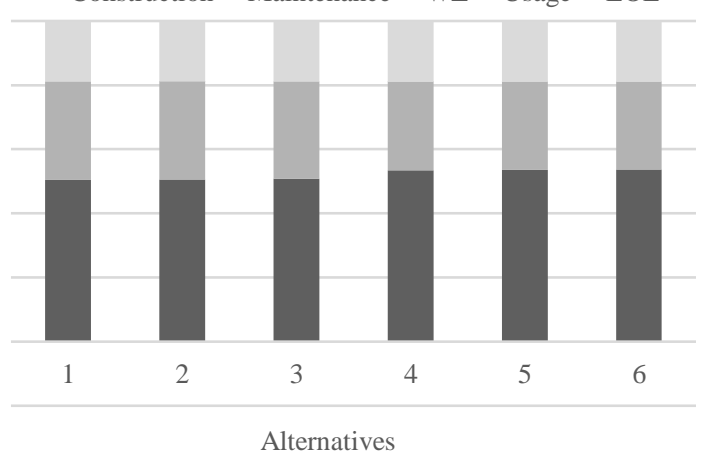

(h)

\section{Water depletion}

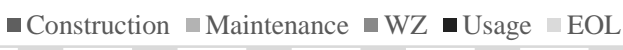

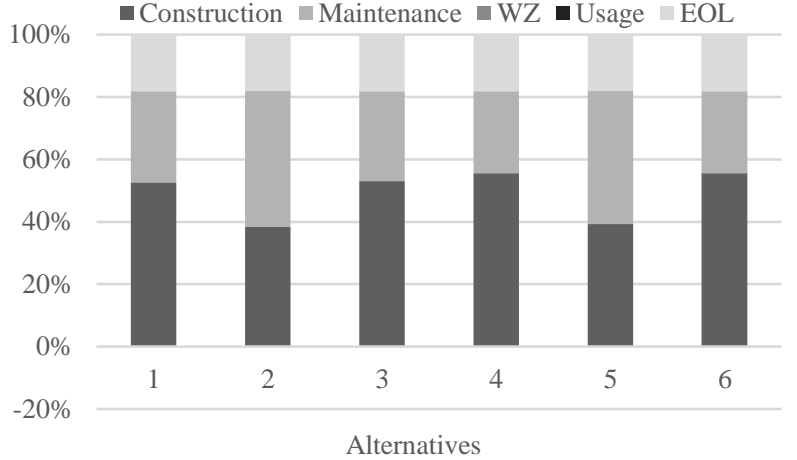

(j)

Non-renewable cumulative energy demand

-Construction $\square$ Maintenance $\square \mathrm{WZ}$-Usage $\square$ EOL

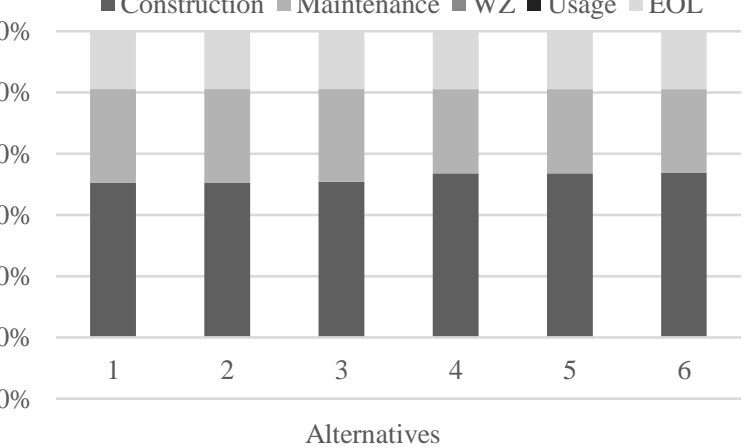

(1) 
Figure 5. Contribution analysis by pavement life cycle phase: a) climate change; b) acidification; c) eutrophication; d) human toxicity; e) terrestrial ecotoxicity; f) photochemical oxidation; g) stratospheric ozone depletion; h) abiotic resources depletion; i) particulate matter; j) water depletion; k) renewable cumulative energy demand; l) non-renewable cumulative energy demand. Key: Alternative 1: HMA, 0\%RAP; Alternative 2: WMA- CECABASE ${ }^{\circledR}$, 0\%RAP; Alternative 3: Foamed WMA, 0\%RAP; Alternative 4: HMA, 50\%RAP; Alternative 5: WMA- CECABASE ${ }^{\circledR}$, 50\%RAP; Alternative 6: Foamed WMA, 50\% RAP.

\section{$8 \quad$ 3.2. Scenario analysis}

In order to assess the robustness of the results presented in the previous sub-section to changes in the methodological assumptions, a scenario analysis was performed by considering two alternative scenarios. In the first one, hereafter named AS1, it was assumed that the asphalt plant is run by natural gas rather than by HFO. This is a plausible scenario that stands the best chance of becoming the actual and near-term future practice, thereby replacing the baseline scenario, as new asphalt plants are increasingly switching to natural gas because of its general lower price and cleaner-burning properties. In the second one, hereafter named AS2, it was assumed that the road pavement structure is dismantled at the EOL and the debris transported to an asphalt plant where they will undergo the required processing operations to be considered as RAP. The allocation of the environmental impacts was made in accordance with the considerations underlying to the "cut-off" method described in subsection 2.1.2. The reasoning for the consideration of this alternative lays on the fact that it is commonly considered in the literature as the fate to be given to a road pavement when it reaches the end of its lifetime (Van Dam et al., 2015). Another reason backing the choice of the alternative scenarios pertains to the fact that they evolve directly the pavement life cycle phases driving the global environmental performance of the system being analysed.

Figures 5 displays for each alternative the relative variation of the LCIA results in relation to the baseline scenario. They should be understood as follows: positive relative numbers mean that the alternative scenarios improve the LCIA results in relation to those associated with the baseline scenario while negative numbers represent a worsening of the environmental profile. The results show an almost unanimous reduction in all impacts and energy indicators for both alternative scenarios regardless the pavement construction and M\&R alternative studied. Overall, AS2 leads to a uniform reduction of the scores (13-18\%) of all impact categories across all alternatives being compared. In turn, the consequences resulting from considering the AS1 depend to a great extent on the impact category. The most expressive improvements in the environmental profiles are observed in the TE indicator (57\%) for the alternative HMA, 50\%RAP, while the most feeble improvements are observed in the ARD indicator (slightly lower 1\%) for the alternative Foamed WMA, 0\%RAP.

Notwithstanding the overall environmental benefits that can be achieved with both alternative scenarios, there is, however, an exception. It was observed in the alternative scenario AS1 for the energy indicator R-CED. This scenario increases the aforementioned indicator by $2-3 \%$ across the six alternatives, though it leads to a reduction of the total CED. The latter result is far more important than the consideration of the former isolatedly, as its explanation lays on the reduction of the NR-CED.

When comparing the extent to which the alternative scenarios affects the variation of the scores of a given impact category across the alternatives being compares, Figure 6 shows that AS1 originates environmental profiles that are slightly more prone to vary in relation to the baseline scenario, than those associated with the AS2. Also, among the six alternatives the greatest reductions in the environmental impacts scores are obtained for the alternative HMA, 50\%RAP. Moreover, the environmental performances of the alternatives incorporating RAP seem to be less susceptible to variations when the AS2 is assumed to be implemented comparatively to the scenario in which the pavement structure is supposed to be dismantled at the end of its lifetime (AS2). 
Finally, the results of the scenario analysis indicate that shifting the type of fuel consumed by asphalt plants from HFO to natural gas offers considerable potential environmental benefits and a more trustworthy option, as it refers to a decision made in the present with immediate consequences, whereas those associated with the AS2 depend on a decision which will be made far in the future, and thereby 5 entails a great deal of uncertainty.

6
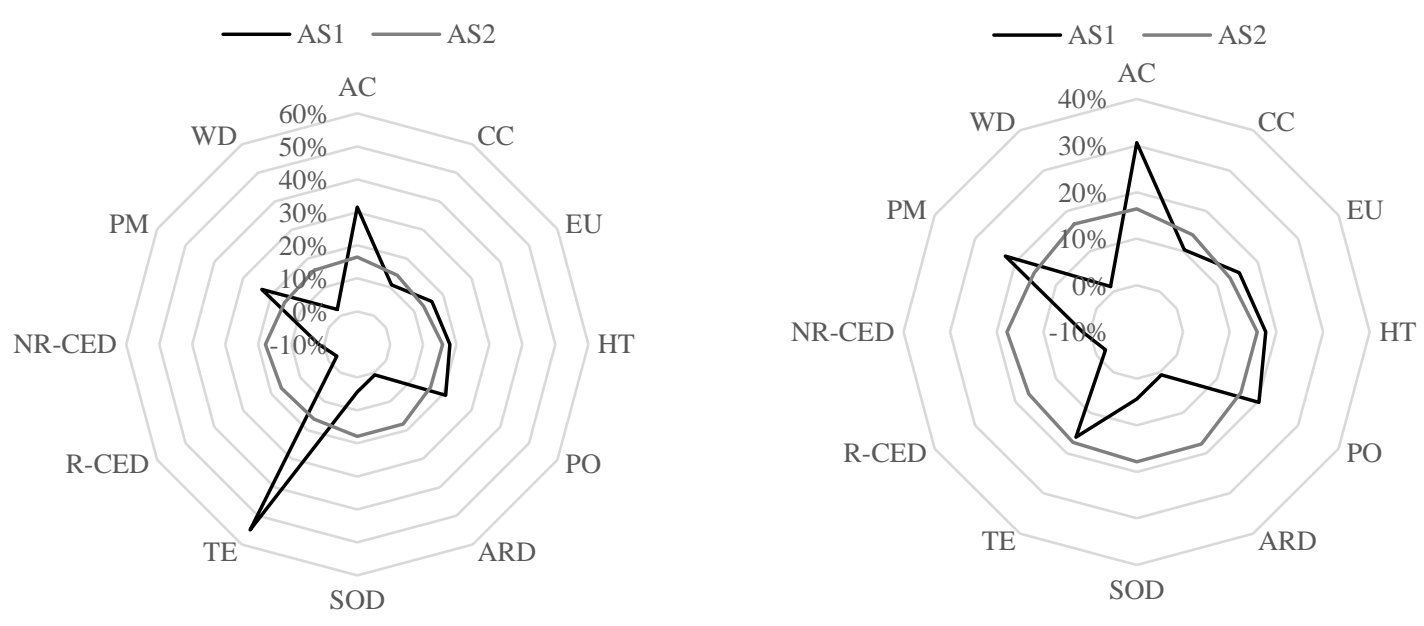

(a)

(b)
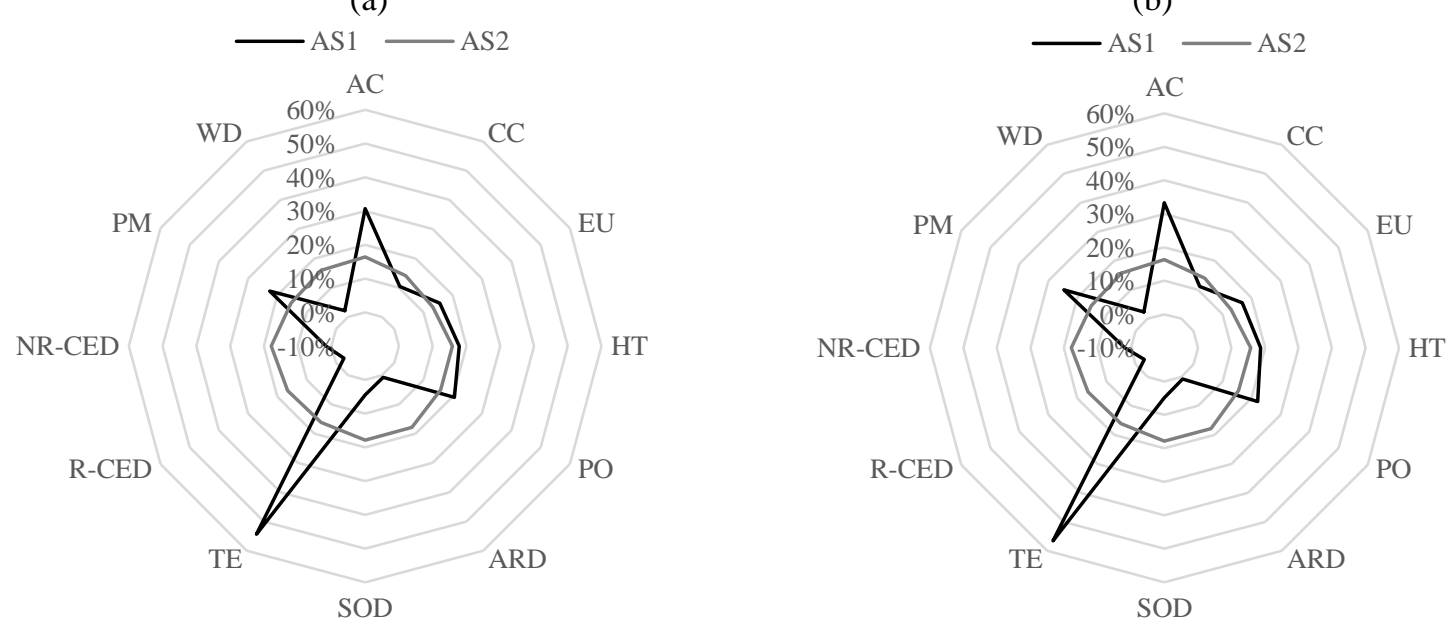

(c)

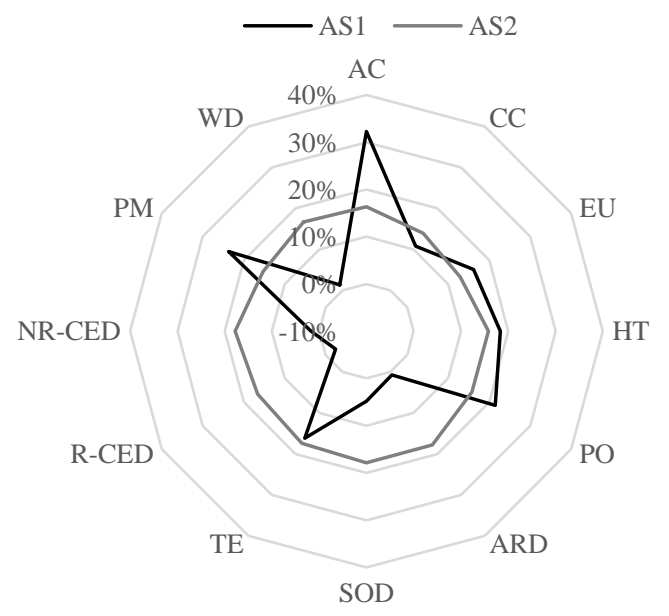

(d)

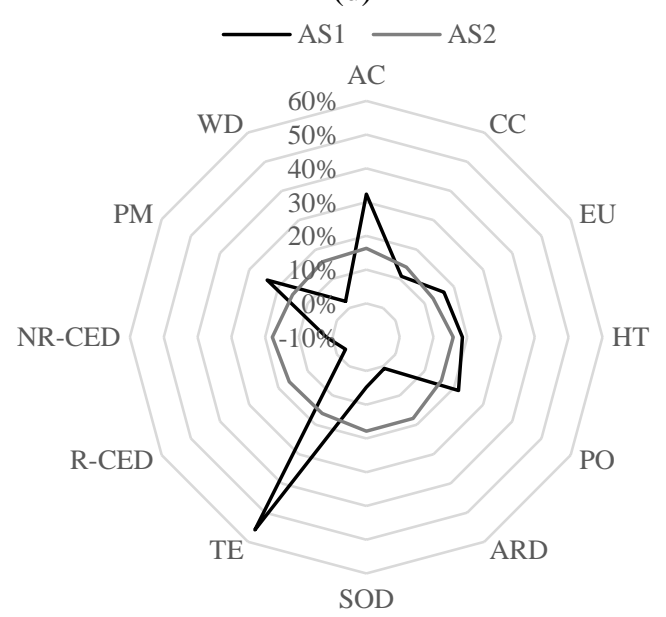

(e)

(f)

7 Figure 6. Relative variation of the LCIA results in relation to the baseline scenario: a) Alternative 1: HMA, 8 0\%RAP; b) Alternative 2: WMA- CECABASE ${ }^{\circledR}, 0 \%$ RAP; c) Alternative 3: Foamed WMA, 0\% RAP; d) 
Alternative 4: HMA, 50\% RAP; e) Alternative 5: WMA- CECABASE ${ }^{\circledR}$, 50\%RAP; f) Alternative 6: Foamed WMA, 50\%RAP. Acronyms: AS1- alternative scenario 1; AS2- alternative scenario 2; CC- Climate Change; AC- Acidification; EU- Eutrophication; HT- Human toxicity; TE- Terrestrial ecotoxicity; POPhotochemical oxidation; SOD- Stratospheric ozone layer depletion; ARD- Abiotic resources depletion; PM- Particulate matter formation; WD- Water depletion; NR-CED- Non-renewable cumulative energy demand; R-CED- Renewable cumulative energy demand.

\section{Summary and conclusions}

In this paper, the results of a comprehensive process-based LCA of French road pavement sections incorporating alternatively two different WMA technologies, with and without RAP content, were presented and compared with those in which conventional HMA mixtures, also with and without RAP content, were adopted. The life cycle of the road pavement sections was divided into six main phases: (1) materials extraction and mixtures production; (2) construction and M\&R; (3) transportation of materials; (4) WZ traffic management; (5) usage; and (6) EOL. The LCI of inputs and outputs associated with the processes considered by the several pavement life cycle phases was determined by combining primary data, representing the current French practices and conditions, with secondary data taken primarily from the ecoinvent database version 3.2 and complemented with publicly available reports. Complementary, an energy balance model was developed to account for the energy required to produce the several mixtures studied, as well as the airborne emissions released during their production, as a function of the mixing temperature and the features of the mixtures components. The CML 2001 impact assessment method along with the CED indicator were adopted to characterize the environmental performance of the following asphalt mixtures: (1) conventional HMA, 0\% RAP; (2) WMACECABASE $^{\circledR}, 0 \%$ RAP; (3) Foamed WMA, 0\% RAP; (4) HMA, 50\% RAP; (5) WMA- CECABASE ${ }^{\circledR}$, $50 \%$ RAP; and (6) Foamed WMA, 50\% RAP.

The LCIA results of the case study showed that, for the mixtures studied and assumptions performed, the pavement construction and M\&R scenario in which the mixture Foamed WMA, 50\% RAP is employed in the wearing course throughout the pavement life cycle is the most environmentally friendly alternative among all the competing solutions. Regarding the results referring to the relative contribution of the several processes included in the systems boundaries, it was shown that, overall, the production of the bitumen is the main responsible for the life cycle environmental burdens of the systems studied. Moreover, when comparing the contribution given by the several pavement life cycle phases, the materials extraction and mixtures production was found to be the phase that plays the most important role in driving the life cycle environmental performance of the road pavement sections analysed. Finally, the results of a scenario analysis showed that the life cycle environmental impacts could be reduced if the asphalt plant was fueled by natural gas, or if the pavement structure was dismantled at the end of its lifetime and the debris recycled.

\section{Acknowledgements and disclaimer}

The research presented in this paper was carried out as part of the Marie Curie Initial Training Network (ITN) action, FP7-PEOPLE-2013-ITN. This project has received funding from the European Union's Seventh Framework Program for research, technological development and demonstration under grant agreement number 607524.

The contents of this paper reflect the views of the authors, who are responsible for the facts and the accuracy of the data presented. Any inclusion of manufacturer names, trade names, or trademarks is for identification purposes only and is not to be considered an endorsement. Moreover, this paper does not constitute a standard, specification, or regulation.

\section{References}


AFNOR, French Standardisation Agency, 2004. Environmental Quality of Construction Products Environmental and Health Declaration of Construction Products. AFNOR. 47pp.

Al-Omari, B., Darter, M., 1994. Relationships between international roughness index and present serviceability rating. Transp. Res. Rec. J. Transp. Res. Board. 1435, 130-136.

American Association of State Highway and Transportation Officials (AASHTO), 1993. Guide for design of pavement structures. $4^{\text {th }}$ ed. Washington, DC.

Almeida-Costa, A., Benta, A., 2016. Economic and environmental impact study of warm mix asphalt compared to hot mix asphalt. J Clean Prod. 112, 2308-2317. http://dx.doi.org/10.1016/j.jclepro.2015.10.077.

Aurangzeb, Q., Al-Qadi, I., Ozer, H. and Yang, R., 2014. Hybrid life cycle assessment for asphalt mixtures with high RAP content. Resour. Conserv. Recycl. 83, 77-86. http://dx.doi.org/10.1016/j.resconrec.2013.12.004.

Bryce, J., Santos, J., Flintsch, G., Katicha, S., McGhee, K., Ferreira, A., 2014. Analysis of rolling resistance models to analyze vehicle fuel consumption as a function of pavement properties. Proceedings of the $3^{\text {rd }}$ International Symposium on Asphalt Pavements and Environment, in Asphalt Pavements, Y. Richard Kim, CRC Press 2014, 263-273, Print ISBN: 978-1-138-02693-3, eBook ISBN: 978-1-315-73675-4, DOI: 10.1201/b17219-39, Raleigh, North Carolina, USA.

D’Angelo, J., Harm, E., Bartoszek, J., Baumgardner, G., Corrigan, M., Cowsert, J., Harman, T., Jamshidi, M., Jones, W., Newcomb, D., Prowell, B., Sines, R., Yeaton, B., 2008. Warm-mix Asphalt: European Practice. Report No. FHWA/PL-08/007, Federal Highway Administration, Washington, DC. https://international.fhwa.dot.gov/pubs/p108007/p108007.pdf.

Dahlbo, H., Koskela, S., Pihkola, H., Nors, M., Federlay, M., Seppälä, J., 2013. Comparison of different normalised LCIA results and their feasibility in communication. Int J Life Cycle Assess. 18, 850860. http://dx.doi.org/10.1007/s11367-012-0498-4.

EN, 2013. EN 15804+A1 Sustainability of construction works - Environmental product declarations Core rules for the product category of construction products.

EMISIA, 2017. EMISIA. Copert v5. http://emisia.com/products/copert.

Eurobitume, 2011. Life cycle inventory: bitumen. Eurobitume.

European Commission, Joint Research Center - Institute for Environment and Sustainability (EC, JRC - IES), 2010. International reference life cycle data system (ILCD) handbook - general guide for life cycle assessment - detailed guidance. First edition March 2010. EUR 24708 EN. Luxembourg: Publications Office of the European Union.

Federal Highway Administration (FHWA), 2016. Strategies for improving the sustainability of asphalt pavements. Tech brief. Report No. FHWA-HIF-16-012. Federal Highway Administration, Washington, DC. https://www.fhwa.dot.gov/pavement/sustainability/hif16012.pdf.

Frischknecht, R., Jungbluth, N., Althaus, H.-J., Bauer, C., Doka, G., Dones, R., Hischier, R., Hellweg, S., Humbert, S., Köllner, T., Loerincik, Y., Margni, M., Nemecek T., 2007. Implementation of Life Cycle Impact Assessment Methods. ecoinvent report No. 3, v2.0. Swiss Centre for Life Cycle Inventories, Dübendorf.

Giani, M., Dotelli, G., Brandini, N., Zampori, L., 2015. Comparative life cycle assessment of asphalt pavements using reclaimed asphalt, warm mix technology and cold in-place recycling. Resour. Conserv. Recycl. 104, 224-238. http://dx.doi.org/10.1016/j.resconrec.2015.08.006.

Goedkoop, M., Heijungs, R., Huijbregts, M., De Schryver, A., Struijs, J., van Zelm, R., 2013. ReCiPe 2008- a life cycle impact assessment method which comprises harmonized category indicators at the midpoint and the endpoint level. Ministerie van VROM, Den Haag.

Guinee, J., Gorree, M., Heijungs, R., Huppes, G., Kleijn, R., de Koning, A., van Oers, L., Sleeswijk, A., Suh, S., Udo de Haes, H., de Bruijn, H., van Duin, R., Huijbregts, M., 2002. Handbook on 
lifecycle assessment. Operational guide to the ISO standards. I: LCA in perspective. IIa: guide. IIb: operational annex. III: scientific background. Kluwer Academic Publishers, Dordrecht.

Hammarström, U., Eriksson, J., Karlsson, R., Yahya, M.-R., 2012. A rolling resistance model, a fuel consumption model and the traffic energy saving potential from changed road surface condition. VTI Report 748A. The Swedish National Road and Transport Research Institute.

Hamzah, M., Jamshidi, A., Shahada, Z., 2010. Evaluation of the potential of Sasobit ${ }^{\circledR}$ to reduce required heat energy and CO2 emission in the asphalt industry. J Clean Prod. 18, 1859-1865. http://dx.doi.org/10.1016/j.jclepro.2010.08.002.

Harvey, J., Meijer, J., Ozer, H., Al-Qadi, I., Saboori, A., Kendall, A., 2016. Pavement Life-Cycle Assessment Framework. Report No FHWA-HIF-16-014, Federal Highway Administration, Washington, DC. https://www.fhwa.dot.gov/pavement/sustainability/hif16014.pdf

IEA, 2005. Energy statistics manual. France: IED Publications.

International Standard Organization (ISO), 2006a. ISO 14040: 2006. International Standard ISO 14040: Environmental Management - Life Cycle Assessment: Principles and Framework, October. Geneva (Switzerland). International Organization for Standardization.

International Standard Organization (ISO), 2006b. ISO 14044:2006. International Standard ISO 14044: Environmental Management - Life Cycle Assessment: Requirements and Guidelines, October. Geneva (Switzerland). International Organization for Standardization.

Jones, W., 2004. Warm mix asphalt-a state-of-the-art review. Australian Asphalt Pavement Association Advisory Note, 17.

Jullien, A., Dauvergne, M., Cerezo, V., 2014. Environmental assessment of road construction and maintenance policies using LCA. Transp. Res. Part Transp. Environ. 29, 56-65. http://dx.doi.org/10.1016/j.trd.2014.03.006.

Jullien, A., Cerezo, V., Keijzer, E., Lòpez, A.-M., 2015. ECOLABEL. Deliverable D1.4: benchmarking exercise to assess the set of proposed indicators in diverse road case studies. 1-106.

Kristjánsdóttir, Ó., Muench, S., Michael, L., Burke, G., 2007. Assessing potential for warm-mix asphalt technology adoption. Transp. Res. Rec. J. Transp. Res. Board. 2040, 91-99. http://dx.doi.org/10.3141/2040-10.

Lo Presti, D., Airey, G., Rubio, M., Marsac, P., 2017. SUP\&R ITN: an international training network on sustainable pavements and railways, in: Dell'Acqua, G. and Wegman, F. (Eds), Transport Infrastructure and Systems: Proceedings of the Aiit International Congress on Transport Infrastructure and Systems (TIS 2017), Rome, Italy, 10-12 April 2017, CRC Press/Balkema P.O. Box 11320, 2301 EH Leiden, The Netherlands CRC Press/Balkema 2017, pp. 47-54, Print ISBN: 978-1-138-03009-1. https://doi.org/10.1201/9781315281896-9.

Lorino, T., Lepert, P., Giacobi, C., Layerle. E., 2008. Pavement surface characteristics evolution. SURF 2008, France. 1-17.

Matthews, H., Hendrickson, C., Matthews, D., 2015. Life cycle assessment: quantitative approaches for decisions that matter. Green Design Institute, Carnegie Mellon University, Pittsburgh.

Mohammad, L., Hassan, M., Vallabhu, B., Kabir, M., 2015. Louisiana's experience with WMA technologies: mechanistic, environmental, and economic analysis. J Mater Civil Eng. 27, 04014185. http://dx.doi.org/10.1061/(ASCE)MT.1943-5533.0001143.

GreenDelta, 2016. Open LCA. Available at: http://www.openlca.org.

Rodríguez-Alloza, A., Malik, A., Lenzen, M., Gallego, J., 2015. Hybrid input-output life cycle assessment of warm mix asphalt mixtures. J Clean Prod. 90, 171-182. http://dx.doi.org/10.1016/j.jclepro.2014.11.035.

Rubio, M., Moreno, F., Martínez-Echevarría, M., Martínez, G. and Vázquez, J., 2013. Comparative analysis of emissions from the manufacture and use of hot and half-warm mix asphalt. J Clean Prod. 41, 1-6. http://dx.doi.org/10.1016/j.jclepro.2012.09.036. 
Santos, J., Flintsch, G., Ferreira, A., 2017. Environmental and economic assessment of pavement construction and management practices for enhancing pavement sustainability. Resour. Conserv. Recycl. 116, 15-31. http://dx.doi.org/10.1016/j.resconrec.2016.08.025.

Santos, J., Ferreira, A., Flintsch, G., 2015a. A life cycle assessment model for pavement management: methodology and computational framework. Int. J. Pavement Eng. 16, 268-286. http://dx.doi.org/10.1080/10298436.2014.942861.

Santos, J., Bryce, J., Flintsch, G., Ferreira, A., Diefenderfer, B., 2015b. A life cycle assessment of inplace recycling and conventional pavement construction and maintenance practices. Struct. Infrastruct. Eng.: Maint. Manag. Life-Cycle Des. Perform. 11, 1199-1217. http://dx.doi.org/10.1080/15732479.2014.945095.

Santucci, L., 2010. Warm mix asphalt hits the road. Pavement Technology Update, The University of California Pavement Research Center. Technology Transfer Program, 2(1), 1-12. http://www.techtransfer.berkeley.edu/sites/default/files/pave-tech/prc_update_vol2_no1.pdf.

Schrijvers, D., Loubet, P., Sonnemann, G., 2016a. Critical review of guidelines against a systematic framework with regard to consistency on allocation procedures for recycling in LCA. Int J Life Cycle Assess. 21, 994-1008. http://dx.doi.org/10.1007/s11367-016-1069-x.

Schrijvers, D., Loubet, P., Sonnemann, G., 2016b. Developing a systematic framework for consistent allocation in LCA. Int J Life Cycle Assess. 21, 976-993. http://dx.doi.org/10.1007/s11367-0161063-3.

Stimilli, A., Virgili, A., Canestrari, F., 2017. Warm recycling of flexible pavements: effectiveness of Warm Mix Asphalt additives on modified bitumen and mixture performance. J Clean Prod. 156, 911-922. http://dx.doi.org/10.1016/j.jclepro.2017.03.235.

Tatari, O., Nazzal, M., Kucukvar, M., 2012. Comparative sustainability assessment of warm-mix asphalts: a thermodynamic based hybrid life cycle analysis. Resour. Conserv. Recycl. 58, 18-24. http://dx.doi.org/10.1016/j.resconrec.2011.07.005.

Thives, L., Ghisi, E., 2017. Asphalt mixtures emission and energy consumption: a review. Renewable Sustainable Energy Rev. 72, 473-484. http://dx.doi.org/10.1016/j.rser.2017.01.087.

Transportation Research Board (TRB), 2000. Highway Capacity Manual 2000. Transportation Research Board, Washington, DC.

Van Dam, T., Harvey, J., Muench, S., Smith, K., Snyder, M., Al-Qadi, I., Ozer, H., Meijer, J., Ram, P., Roesler, J., Kendall, A., 2015. Towards sustainable pavement systems- a reference document. Report No. FHWA-HIF-15-002, Federal Highway Administration, Washington, DC.

Vidal, R., Moliner, E., Martínez, G., Rubio, M., 2013. Life cycle assessment of hot mix asphalt and zeolite-based warm mix asphalt with reclaimed asphalt pavement. Resour. Conserv. Recycl. 74, 101-114. http://dx.doi.org/10.1016/j.resconrec.2013.02.018.

Washington State University, Pennsylvania State University-Altoona, Louisiana Transportation Research Center, 2017. Long-term field performance of warm mix asphalt technologies. NCHRP Research Report 843, Transportation Research Board, Washington, D.C.

West, R., Rodezno, C., Julian, G., Prowell, B., Frank, B., Osborn, L., Kriech, T., 2014. Field Performance of Warm Mix Asphalt Technologies (National Cooperative Highway Research Program Report No. 779). Transportation Research Board, Washington, D.C.

Yang, X., You, Z., Hasan, M., Diab, A., Shao, H., Chen, S., Ge, D., 2017. Environmental and mechanical performance of crumb rubber modified warm mix asphalt using Evotherm. J Clean Prod. 159, 346-358. http://dx.doi.org/10.1016/j.jclepro.2017.04.168.

Zaumanis, M., 2014. Warm mix asphalt, in: Gopalakrishnan, K., Steyn, W., Harvey, J. (Eds.), Climate Change, Energy, Sustainability and Pavements, Green Energy and Technology, Springer-Verlag. http://dx.doi.org/10.1007/978-3-662-44719-2_10. 